\section{(1) \\ CrossMark}

\title{
ERS statement on obstructive sleep disordered breathing in 1- to 23-month-old children
}

\author{
Athanasios G. Kaditis ${ }^{1}$, Maria Luz Alonso Alvarez², An Boudewyns ${ }^{3}$, \\ Francois Abel ${ }^{4}$, Emmanouel I. Alexopoulos ${ }^{5}$, Refika Ersu ${ }^{6}$, Koen Joosten ${ }^{7}$, \\ Helena Larramona ${ }^{8}$, Silvia Miano ${ }^{9}$, Indra Narang ${ }^{10}$, Hui-Leng Tan ${ }^{11}$, Ha Trang ${ }^{12}$, \\ Marina Tsaoussoglou ${ }^{1}$, Nele Vandenbussche ${ }^{13}$, Maria Pia Villa ${ }^{14}$, \\ Dick Van Waardenburg ${ }^{15}$, Silke Weber ${ }^{16}$ and Stijn Verhulst ${ }^{17}$
}

@ERSpublications

Obstructive sleep disordered breathing in young children is a heterogeneous group of disorders http://ow.ly/qqgc30fGvaj

Cite this article as: Kaditis AG, Alonso Alvarez ML, Boudewyns A, et al. ERS statement on obstructive sleep disordered breathing in 1- to 23-month-old children. Eur Respir J 2017; 50: 1700985 [https://doi.org/ 10.1183/13993003.00985-2017].

ABSTRACT The present statement was produced by a European Respiratory Society Task Force to summarise the evidence and current practice on the diagnosis and management of obstructive sleep disordered breathing (SDB) in children aged 1-23 months. A systematic literature search was completed and 159 articles were summarised to answer clinically relevant questions. SDB is suspected when symptoms or abnormalities related to upper airway obstruction are identified. Morbidity (pulmonary hypertension, growth delay, behavioural problems) and coexisting conditions (feeding difficulties, recurrent otitis media) may be present. SDB severity is measured objectively, preferably by polysomnography, or alternatively polygraphy or nocturnal oximetry. Children with apparent upper airway obstruction during wakefulness, those with abnormal sleep study in combination with SDB symptoms (e.g. snoring) and/or conditions predisposing to SDB (e.g. mandibular hypoplasia) as well as children with SDB and complex conditions (e.g. Down syndrome, Prader-Willi syndrome) will benefit from treatment. Adenotonsillectomy and continuous positive airway pressure are the most frequently used treatment measures along with interventions targeting specific conditions (e.g. supraglottoplasty for laryngomalacia or nasopharyngeal airway for mandibular hypoplasia). Hence, obstructive SDB in children aged 1-23 months is a multifactorial disorder that requires objective assessment and treatment of all underlying abnormalities that contribute to upper airway obstruction during sleep.

This document was endorsed by the ERS Science Council and Executive Committee in September 2017.

This article has supplementary material available from erj.ersjournals.com

Received: May 142017 | Accepted after revision: Aug 162017

Support statement: The European Respiratory Society financially supported this Task Force (ERS Task Force 2012-09) through organisation of meetings and travel expenses of its members for the purpose of preparing the current statement. Funding information for this article has been deposited with the Crossref Funder Registry.

Conflict of interest: None declared.

Copyright @ERS 2017 
Affiliations: ${ }^{1}$ Paediatric Pulmonology Unit, First Dept of Paediatrics, National and Kapodistrian University of Athens School of Medicine and Aghia Sophia Children's Hospital, Athens, Greece. ${ }^{2}$ Multidisciplinary Sleep Unit, Pulmonology, University Hospital of Burgos and CIBER of Respiratory Diseases (CIBERES), Burgos Foundation for Health Research, Burgos, Spain. ${ }^{3}$ Dept of Otorhinolaryngology Head and Neck Surgery, Antwerp University Hospital, University of Antwerp, Antwerp, Belgium. ${ }^{4}$ Dept of Respiratory Medicine, Great Ormond Street Hospital for Children, London, UK. ${ }^{5}$ Sleep Disorders Laboratory, University of Thessaly School of Medicine and Larissa University Hospital, Larissa, Greece. ${ }^{6}$ Division of Paediatric Pulmonology, Marmara University, Istanbul, Turkey. ${ }^{7}$ Erasmus MC, Sophia Children's Hospital, Paediatric Intensive Care, Rotterdam, The Netherlands. ${ }^{8}$ Paediatric Pulmonology Unit, Dept of Paediatrics, University Autonoma of Barcelona, Corporacio Sanitaria Parc Tauli, Hospital of Sabadell, Barcelona, Spain. 'Sleep and Epilepsy Centre, Neurocentre of Southern Switzerland, Civic Hospital of Lugano, Lugano, Switzerland. ${ }^{10}$ Division of Respiratory Medicine, Hospital for Sick Children, University of Toronto, Toronto, ON, Canada. ${ }^{11}$ Dept of Paediatric Respiratory Medicine, Royal Brompton Hospital, London, UK. ${ }^{12}$ Paediatric Sleep Centre, Robert Debré University Hospital, EA 7334 REMES Paris-Diderot University, Paris, France. ${ }^{13}$ Sleep Medicine Centre, Kempenhaeghe Foundation, Heeze, The Netherlands. ${ }^{14}$ Paediatric Sleep Disease Centre, Child Neurology, NESMOS Dept, School of Medicine and Psychology, Sapienza University of Rome, S. Andrea Hospital, Rome, Italy. ${ }^{15}$ Paediatric Intensive Care Unit, Dept of Paediatrics, Maastricht University Medical Center, Maastricht, The Netherlands. ${ }^{16}$ Dept of Ophthalmology, Otolaryngology and Head and Neck Surgery, Botucatu Medical School, São Paulo State University-UNESP, Botucatu, São Paulo, Brazil. ${ }^{17}$ Dept of Paediatrics, Antwerp University Hospital, Edegem, Belgium.

Correspondence: Athanasios G. Kaditis, Paediatric Pulmonology Unit, First Dept of Paediatrics, University of Athens School of Medicine and Aghia Sophia Children's Hospital, Athens 11527, Greece.

E-mail: kaditialahotmail.com

\section{Introduction}

Obstructive sleep disordered breathing (SDB) is not a distinct disease, but rather a syndrome of upper airway dysfunction during sleep characterised by snoring and/or increased respiratory effort secondary to increased upper airway resistance and pharyngeal collapsibility [1,2]. Diagnosis and management of obstructive SDB in children aged 2-18 years have been summarised in a previous European Respiratory Society Statement (ERS) Statement [3]. Children aged $<2$ years represent a unique subgroup with predisposition to upper airway obstruction and not uncommonly with symptoms during wakefulness, and thus require age-appropriate interventions.

Obstructive SDB includes a spectrum of clinical entities with variable severity of intermittent upper airway obstruction (table 1) [4,5]. Obstructive sleep apnoea syndrome (OSAS) is the main abnormality reported in the first 1-23 months of life, whereas the terms primary snoring, upper airway resistance syndrome and obstructive hypoventilation are used far less frequently in the literature. The apnoea-hypopnoea index (AHI), defined as the number of mixed, obstructive and central apnoeas and hypopnoeas per hour of total sleep time, and the obstructive AHI (central apnoeas excluded) are the most commonly used polysomnographic parameters for the description of SDB severity.

In adults, the term "obstructive sleep apnoea" (OSA) indicates intermittent upper airway obstruction during sleep reflected by AHI $\geqslant 5$ episodes $\cdot h^{-1}$, whereas "OSAS" is used for patients with AHI $\geqslant 5$ episodes $\cdot \mathrm{h}^{-1}$ in the presence of daytime sleepiness [6]. In the experience of the Task Force members, OSAS in children frequently incorporates both an elevated obstructive AHI and the presence of symptoms of upper airway obstruction during sleep (snoring or "noisy" breathing, or increased work of breathing) that are reported by parents or recorded during polysomnography.

Mild central sleep apnoea (cessation of airflow without respiratory effort) is common even in otherwise healthy infants; the long-term consequences are unclear and it usually resolves with age [7,8]. Apnoea of prematurity and central sleep apnoea are not discussed in this statement, which is focused on obstructive SDB.

\section{Unique characteristics of this ERS statement}

The unique characteristics of this statement compared with other documents [4, 9-15] (see supplementary material) are as follows. 1) It focuses exclusively on obstructive SDB in children aged 1-23 months. 2) It discusses conditions predisposing to obstructive SDB, such as craniofacial abnormalities, neuromuscular disorders and genetic syndromes. 3) It takes into account the available diagnostic facilities and accepted treatment policies in different European countries, and describes diagnostic modalities that can be used as alternatives for settings where polysomnography is not available. 4) It summarises the published evidence and the current practice of the ERS Task Force members on the diagnosis and management of obstructive SDB in young children, but it does not intend to provide recommendations for clinical practice.

In the current statement the terms "infant" and "young child" are used to denote subjects aged 1-12 and 1-23 months, respectively. 
TABLE 1 Definitions of obstructive sleep disordered breathing (SDB) and its clinical entities

Definition

$\begin{array}{ll}\text { Obstructive SDB } & \begin{array}{c}\text { A syndrome of upper airway dysfunction during sleep characterised by snoring and/or increased } \\ \text { respiratory effort that result from increased upper airway resistance and pharyngeal collapsibility }\end{array} \\ \begin{array}{c}\text { Clinical entities } \\ \text { Primary snoring }\end{array} & \begin{array}{c}\text { Habitual snoring ( }>3 \text { nights per week) without apnoeas, hypopnoeas, frequent arousals from sleep or gas } \\ \text { exchange abnormalities } \\ \text { Snoring, increased work of breathing, frequent arousals, but no recognisable obstructive events or gas } \\ \text { exchange abnormalities }\end{array} \\ \begin{array}{c}\text { Upper airway resistance } \\ \text { syndrome }\end{array} \\ \begin{array}{c}\text { Obstructive hypoventilation and abnormally elevated partial pressure of carbon dioxide in the absence of recognisable } \\ \text { obstructive events }\end{array} \\ \begin{array}{c}\text { Obstructive sleep apnoea } \\ \text { syndrome }\end{array} \\ \text { apnoeas) with disruption of normal oxygenation, ventilation and sleep pattern }\end{array}$

Information from $[4,5]$.

\section{Methods}

Experts on paediatric respiratory and sleep medicine, paediatric neurology, and paediatric otorhinolaryngology from several European countries and countries outside Europe who are active within the ERS participated in the Task Force (ERS Task Force TF-2012-09). All members signed forms disclosing conflicts of interest annually. The first ERS statement for children aged 2-18 years was published in February 2016 [3].

This statement contains a series of clinically relevant questions (topics), formed by consensus of all members during two face-to-face meetings. A systematic search of the literature was completed by the two chairs of the Task Force to answer the formulated questions. The MEDLINE, Scopus, PsycINFO, EBSCO and CINAHL databases were searched for the period between January 1970 and December 2016. Key words included: "adenoidectomy"; "adenoidal hypertrophy"; "adenotonsillar hypertrophy"; "polysomnography"; "sleep apnoea”; "sleep-disordered breathing”; "sleep-related breathing disorders"; "snoring"; "tonsillar hypertrophy"; "tonsillectomy"; "continuous positive airway pressure"; "non-invasive positive pressure ventilation". The search was limited to articles in the English language and humans aged $0-23$ months.

The methodological quality of articles was graded as class I-IV according to the American Academy of Neurology Clinical Practice Guideline Process Manual, with class I indicating the highest quality evidence [16]. More details on Methods can be found in the supplementary material. A stepwise approach to the management of obstructive SDB in this age group reflecting the current practice of the Task Force members was also prepared (figure 1). However, this scheme is not intended as a general recommendation.

\section{Results of the literature search}

The initial search provided 5146 titles. After excluding articles on neonates, apnoea of prematurity, OSAS in adults or non-humans, articles not related to SDB as well as abstracts, letters and case reports, 4647 titles remained and 3975 of them were in the English language. Finally, 159 references were relevant to the formulated questions and were used in the current statement. Summaries of studies included in this statement along with grading of their methodological quality are presented in the supplementary material. The majority of the included studies were of low quality because they were uncontrolled. More specifically: 1) they did not recruit patients undergoing different interventions (therapeutic studies), or 2) they did not include subjects without risk factors for OSAS or its complications (causation or prognostic studies) [16].

\section{Topic 1: recognition of the young child at risk for OSAS}

\subsection{Which symptoms reported by parents are directly related to OSAS?}

Evidence summary

a) Snoring or "noisy" breathing is the commonest symptom directly related to OSAS during the first 2 years of life followed in frequency by apnoeas, frequent movements during sleep, mouth breathing and recurrent awakenings.

b) History of apparent life-threatening events (ALTEs; or brief, resolved, unexplained events (BRUE)) may be associated with the presence or development of OSAS. 
STEP 1: At risk for OSAS if (one or more):

1.1 Symptoms of upper airway obstruction (snoring, apnoea, restless sleep, mouth breathing); history of ALTES; unclear whether GOR or prematurity are risk factors

1.2 Delayed growth may be a presenting symptom (and a complication) of OSAS

1.3 Exam findings:

a) Adenoidal or, less frequently, tonsillar hypertrophy

b) Nasal obstruction (upper viral respiratory infection, choanal atresia)

c) Laryngeal obstruction (laryngomalacia)

d) Syndromic craniosynostosis \pm midface hypoplasia; repaired or unrepaired isolated cleft lip or palate

e) Mandibular hypoplasia (e.g. Pierre Robin sequence)

f) Neuromuscular disorders (e.g. cerebral palsy, mitochondrial disorders, spinal muscular atrophy)

g) Complex disorders (e.g. achondroplasia, Down syndrome, Prader-Willi syndrome)

1.4 Upper airway endoscopic or imaging findings (e.g. craniosynostosis, Down syndrome, Pierre Robin sequence)

STEP 2: Recognition of morbidity and conditions coexisting with OSAS:

2.1 Pulmonary hypertension and cor pulmonale

2.2 Delayed somatic growth

2.3 Behavioural problems

2.4 Conditions coexisting with

OSAS:

a) Feeding difficulties las in

Pierre Robin sequencel

b) Recurrent otitis media

STEP 4: Treatment of OSAS:

4.1 When is OSAS treated:

a) Apparent UAO during wakefulness

b) PSG, polygraphy or oximetry abnormalities combined with: i) snoring, tachypnoea or mouth breathing; ii) ALTEs: iii) growth failure

c) PSG, polygraphy or oximetry abnormalities combined with: i) nasal obstructionttonsillar hypertrophy; ii) laryngeal obstruction; iiil syndromic craniosynostosis \pm midface hypoplasia; isolated cleft lip or palate; iv) mandibular hypoplasia; v) neuromuscular disorder

4.2 OSAS treatment is a priority if:

a) Achondroplasia

b) Beckwith-Wiedemann syndrome

c) Chiari malformation

d) Down syndrome

e) Mucopolysaccharidoses

f) Prader-Willi syndrome

\section{STEP 3: Objective diagnosis and assessment of OSAS severity (multidisciplinary} team approach including paediatric pulmonologist, ENT/craniofacial surgeon, intensivist, respiratory physiologist, orthodontist and others):

3.1 Objective tools for diagnosing OSAS severity (video PSG, PSG, polygraphy, nocturnal oximetry]

3.2 AHI cut-off values for defining OSAS and its severity:

a) 90th percentile for obstructive or mixed apnoea or hypopnoea indices $<1$ episode $\cdot \mathrm{h}^{-1}$; higher at high altitude

b) Frequency of central apnoeas varies with age/definition

c) Mild OSAS: obstructive AHI 1-5 episodes $\cdot \mathrm{h}^{-1}$; moderate OSAS: obstructive $\mathrm{AHI}>5-10$ episodes $\cdot \mathrm{h}^{-1}$ : severe OSAS: obstructive $\mathrm{AHI}>10$ episodes $\cdot \mathrm{h}^{-1}$

d) McGill oximetry score $>2$ indicates moderate-to-severe OSAS in Pierre Robin sequence and Down syndrome

3.3 Indications for objective testing: history suggestive of OSAS \pm growth delay (see 1.1 and 1.2); nasal or laryngeal obstruction; midface or mandibular hypoplasia; cleft lip or palate; neuromuscular disorders; complex conditions (see 1.3)

STEP 5: Stepwise, individualised treatment approach (multidisciplinary team management):

5.1 Treatment interventions are individualised according to aetiology, severity and morbidity; upper airway endoscopy for guiding hierarchy of interventions

5.2 Efficacy of antireflux medications is unclear

5.3 Adenoidalttonsillar hypertrophy (midface hypoplasia or other anomalies may be present): adenoidectomy \pm tonsillectomy

5.4 Adenoidectomy from age 3 months; adenotonsillectomy from age 6 months

5.5 CPAP or NPPV: moderate-to-severe OSAS llaryngomalacia; midface or mandibular hypoplasia; cerebral palsy; spinal muscular atrophy; achondroplasia; Down syndrome; mucopolysaccharidoses)

5.6 Interventions for OSAS related to specific conditions:

a) Choanal atresia; nasal pyriform aperture stenosis: surgical correction

b) Laryngomalacia: supraglottoplasty

c) Craniosynostosis \pm midface hypoplasia: adenoidectomy \pm tonsillectomy; nasopharyngeal airway insertion; nCPAP; midface distraction osteogenesis; tracheostomy

d) Mandibular hypoplasia: Pierre Robin sequence: Step 1: prone positioning (McGill oximetry score $\leqslant 2$, no pharyngeal collapse on endoscopy); Step 2: nasopharyngeal airway (McGill oximetry score >2), orthodontic appliance, nCPAP (usually if $A H I>10$ episodes $\cdot h^{-1}$ ) or glossopexy; urgent intubation if severe UAO and possibly tracheostomy; frequently nasogastric tube/gastrostomy feeding

e) Mandibular distraction osteogenesis: Pierre Robin sequence ( \pm other airway lesions)+respiratory distress+hypercapnia+CPAP failure to avoid tracheostomy; or for decannulation after tracheostomy

5.7 Tracheostomy: severe upper airway obstruction+other measures failed; awaiting craniofacial surgery (midface hypoplasia; Pierre Robin sequence)

5.8 Patients with complex conditions may require combined interventions:

a) Achondroplasia: adenotonsillectomy; nasopharyngeal airway; CPAP

b) Chiari malformation: adenoidectomy tonsillectomy; CPAP; NPPV; surgical decompression of cervicomedullary junction

c) Down syndrome: adenoidectomy \pm tonsillectomy; supraglottoplasty; CPAP

d) Mucopolysaccharidoses: adenotonsillectomy; CPAP; enzyme replacement therapy; haemopoietic stem cell transplantation

e) Prader-Willi syndrome: adenotonsillectomy for OSAS; oxygen therapy for central sleep apnoeas

STEP 6: Follow-up, recognition and management of persistent OSAS:

6.1 Re-evaluation and outcome monitoring:

a) Adenotonsillectomy: OSAS recurrence can occur $\geqslant 4-6$ months post-operatively; repeat adenoidectomy may be required

b) CPAP: clinical evaluation and nocturnal monitoring every 2-4 months during first year and every 6 months thereafter (confirm continued need, pressure adjustment, upgrade mask sizel

c) NPPV (neuromuscular disease): nocturnal monitoring upon initiation and at least annually

d) Supraglottoplasty: nocturnal monitoring at 1-6 months post-operatively to assess efficacy

e) Pierre Robin sequence: monitoring every 2 months with nasopharyngeal airway in place and after its removal

f) Mandibular distraction osteogenesis: serial nocturnal sleep studies to assess efficacy

FIGURE 1 A stepwise approach to the management of obstructive sleep disordered breathing in 1- to 23-month-old children reflecting the Task Force members' current practice. This scheme is not intended as a recommendation for clinicians. OSAS: obstructive sleep apnoea syndrome; ALTE: apparent life-threatening event; GOR: gastro-oesophageal reflux; ENT: ear, nose and throat; PSG: polysomnography; AHI: apnoeahypopnoea index; UAO: upper airway obstruction; CPAP: continuous positive airway pressure; NPPV: non-invasive positive pressure ventilation; nCPAP: nasal CPAP. 
c) There is no high-quality evidence indicating that infants with regurgitation or a history of prematurity are predisposed to OSAS.

\section{Literature review}

a) The prevalence of snoring $\geqslant 3$ days per week in young children recruited from the community was $9 \%$ in 0 - to 3 -month-old infants, $15 \%$ in 1 -year-old infants and $5.3 \%$ in children aged 2 weeks to 2 years based on parental report [17-19]. In hospital-referred children aged $<18$ months with adenotonsillar hypertrophy and OSAS, snoring was the most common symptom followed by reported apnoeas, frequent movements during sleep, mouth breathing, recurrent awakenings, developmental delay and recurrent respiratory infections $[20,21]$. In a longitudinal, questionnaire study, the prevalence of snoring peaked between age 1.5 and 2.5 years [22].

b) History of ALTEs has been associated with the presence or later development of OSAS and mild facial dysmorphia in studies of low methodological quality [23-28]. In contrast, a large retrospective study including infants with reported episodes of apnoea and/or cyanosis demonstrated normal polysomnographic findings in the majority of participants [29].

c) No consistent association has been found between gastro-oesophageal reflux and OSAS; prematurity as a risk factor for SDB in infancy has not been studied adequately, although there is evidence for its role in older children [3, 30-33].

\subsection{Is delayed growth a frequent clinical presentation in young children with upper airway obstruction? \\ Evidence summary}

Growth failure is a frequent initial clinical manifestation and also a complication of OSAS in young children.

\section{Literature review}

Growth failure is a complication of OSAS as demonstrated in a meta-analysis [34]. It may also be the clinical manifestation leading to the diagnosis of OSAS as other symptoms can be subtle in early life. In a retrospective study of hospital-referred children with adenotonsillar hypertrophy, the body weight percentile decreased between birth and the diagnosis of OSAS [20].

\subsection{Which findings from the physical examination are related to OSAS in 1- to 23-month-old children? \\ Evidence summary}

a) Adenoidal or, less frequently, tonsillar hypertrophy (after the first 6 months of life).

b) Nasal obstruction: acute upper viral respiratory infection, choanal atresia, nasal pyriform aperture stenosis.

c) Laryngomalacia manifested as inspiratory stridor without or with intercostal retractions, episodes of cyanosis, feeding difficulties and growth delay.

d) Syndromic craniosynostosis with midface hypoplasia (Apert syndrome, Crouzon syndrome and Pfeiffer syndrome) or without midface hypoplasia (Muenke syndrome, Saethre-Chotzen syndrome and complex craniosynostosis); unrepaired or repaired isolated cleft lip or palate.

e) Marked mandibular hypoplasia as in non-syndromic and syndromic Pierre Robin sequence (e.g. Treacher Collins syndrome and Stickler syndrome).

f) Neuromuscular disorders (cerebral palsy, mitochondrial disorders and spinal muscular atrophy).

g) Complex abnormalities (achondroplasia, Beckwith-Wiedemann syndrome, Chiari malformation, Down syndrome, mucopolysaccharidoses and Prader-Willi syndrome).

\section{Literature review}

Various congenital or acquired conditions affecting structures from the nose down to the larynx can predispose to OSAS [35].

a) In a retrospective study of infants with OSAS, adenotonsillar hypertrophy was diagnosed as early as 5 months of age [20].

b) Nasal congestion caused by an intercurrent viral respiratory infection may be accompanied by obstructive events [36]. OSAS is a potential complication of unilateral choanal atresia and one of the primary features of bilateral choanal atresia [37]. 
c) The coexistence of laryngomalacia and OSAS is frequently overlooked [33, 38-41]. It resolves spontaneously in up to $80 \%$ of infants, but in the remaining cases intervention is required [42]. Airway lesions such as subglottic stenosis and tracheomalacia coexist with laryngomalacia in up to $50 \%$ of infants, and their frequency increases with increasing severity of upper airway obstruction; an association with gastro-oesophageal reflux disease has also been described [43].

d) OSAS is more prevalent (up to 68\%) in craniosynostosis syndromes and more severe in children with midface hypoplasia (Apert syndrome, Crouzon syndrome and Pfeiffer syndrome) than in those without hypoplasia (e.g. Muenke syndrome or Saethre-Chotzen syndrome) [44]. Mandibular hypoplasia may coexist and contribute to upper airway obstruction. Several of these infants develop OSAS during an upper respiratory tract infection or due to adenotonsillar hypertrophy, but OSAS severity improves over the first 3 years of life $[44,45]$. Infants with cleft lip and/or palate frequently have obstructive respiratory events during sleep [46].

e) Non-syndromic or syndromic Pierre Robin sequence is the constellation of micrognathia, glossoptosis and upper airway obstruction with or without cleft palate, resulting in feeding difficulties, stridor, episodes of cyanosis and OSAS [47,48]. Severity of obstruction varies from mild to life-threatening requiring immediate intubation or tracheostomy (up to $13.4 \%$ of cases) [47, 49-51]. Coexisting unilateral choanal atresia, a small epiglottis allowing the tongue to obstruct the laryngeal opening, laryngomalacia or tracheal stenosis can worsen respiratory distress [52]. Airway obstruction and feeding difficulties may improve with growth over the first year of life $[47,49,53]$.

f) Cerebral palsy and mitochondrial disorders may be accompanied by OSAS [54, 55]. Infants with spinal muscular atrophy type 1 and 2 have increased AHI [56, 57].

g) Infants with achondroplasia have higher AHI than control infants and midface hypoplasia contributes to obstructive events [58]. OSAS has been described in infants with Beckwith-Wiedemann syndrome [59]. Chiari malformation is accompanied by obstructive and central sleep apnoeas and hypoventilation, risk factors being the degree of brainstem crowding at the foramen magnum and/or length of herniation [60, 61]. In infants with Down syndrome, the lowest estimated prevalence of $\mathrm{AHI} \geqslant 2$ episodes $\cdot \mathrm{h}^{-1}$ is $30 \%$ [62]. OSAS, nocturnal hypoxaemia and hypoventilation are frequent findings [63-65]. OSAS is common in children with any of the mucopolysaccharidoses $[66,67]$. Young patients with Prader-Willi syndrome have increased prevalence of OSAS and central sleep apnoeas $\left(\geqslant 5\right.$ episodes $\left.\cdot h^{-1}\right)[68,69]$. With increasing age, the frequency of OSAS increases and the frequency of central sleep apnoeas decreases $[68,69]$.

\subsection{What is the role of upper airway endoscopy and upper airway imaging in the evaluation of OSAS in young children? \\ Evidence summary}

a) Upper airway endoscopy by a flexible instrument helps to determine the level and severity of airway obstruction in cases of congenital stridor, craniofacial abnormalities or complex conditions (e.g. craniosynostosis, Down syndrome and Pierre Robin sequence).

b) Endoscopy can be performed without sedation, but complete examination of the lower airway requires general anaesthesia with the patient breathing spontaneously.

c) Upper airway imaging is useful in the evaluation of patients with craniofacial abnormalities.

\section{Literature review}

$\mathrm{a}+\mathrm{b})$ Few and small studies have evaluated the diagnostic value in otherwise healthy young children with suspected OSAS [70, 71]. Laryngomalacia is a frequent abnormality detected by endoscopy in children with Down syndrome and upper airway obstruction [72]. Moderate-to-severe upper airway obstruction on endoscopic evaluation of children with Pierre Robin sequence was predictive of polysomnography findings $[52,73]$. Sher and colleagues have described four types of pharyngeal airway obstruction in patients with various craniofacial abnormalities, including craniosynostosis and Pierre Robin sequence [74, 75].

c) Upper airway size has been assessed in children with craniofacial abnormalities (nasal pyriform aperture stenosis and Pierre Robin sequence) using craniofacial computed tomography [76-79].

\section{Topic 2: recognition of morbidity and conditions frequently coexisting with OSAS in young children}

2.1. Does OSAS in young children increase the risk of pulmonary hypertension and cor pulmonale?

Evidence summary

Severe OSAS in young children may predispose to pulmonary hypertension. 
Literature review

Right ventricular ejection fraction increases post-adenotonsillectomy in infants and children with oropharyngeal obstruction and OSAS symptoms [80]. Cor pulmonale has been described in case reports of infants with Pierre Robin sequence and severe upper airway obstruction [81, 82].

\title{
2.2. Do young children with OSAS have increased risk for delayed growth?
}

Evidence summary

a) Delayed growth is a complication of OSAS in young children.

b) Younger children with OSAS have higher frequency of growth failure or delay compared with older children.

\section{Literature review}

a) For delayed growth see also 1.2. OSAS may have long-term consequences on growth.

b) Infants aged $<3$ months who underwent supraglottoplasty for laryngomalacia had greater improvement in body mass index percentile post-operatively than older infants [83].

\subsection{Does OSAS in young age affect behaviour and cognitive development?}

Evidence summary

OSAS symptoms in early life (snoring, mouth breathing and witnessed apnoea) are associated with lower cognitive development scores and predict behavioural problems at 4 and 7 years of age.

\section{Literature review}

Obstructive SDB symptoms at 6 and 18 months of age have been related to increased risk for behavioural morbidity and especially hyperactivity at the age of 7 years in a community-based, prospective study [84]. Longitudinal data suggest that frequent snoring in infancy is associated with lower cognitive development scores [85-87]. Increased obstructive AHI in infants with cleft lip and/or palate correlates with lower scores in the behavioural domain at the age of 3 years [88].

\author{
2.4. Which conditions frequently coexist with OSAS (potential common pathogenetic mechanisms) \\ and may improve with OSAS treatment? \\ Evidence summary \\ a) Feeding difficulties. \\ b) Recurrent otitis media.
}

Literature review

a) In a small series of infants with adenotonsillar hypertrophy and OSAS, $\sim 15 \%$ of cases had feeding difficulties [20]. Infants with moderate-to-severe laryngomalacia often present with swallowing and feeding difficulties, especially in the presence of neurological disorders and/or syndromic comorbidities, and may improve after supraglottoplasty $[89,90]$. Pierre Robin sequence is accompanied by feeding difficulties in $80 \%$ of cases, probably due to presence of cleft palate and increased work of breathing [91]. Low weight percentile is not associated with OSAS severity [91].

b) In a retrospective study of children with OSAS aged 3-24 months, the frequency of middle ear effusion requiring surgical treatment was 31.9\% [92]. Infants with Down syndrome and OSAS have increased prevalence of recurrent otitis media [93].

Topic 3: objective diagnosis and assessment of OSAS severity 3.1. What are the objective tools for the diagnosis of OSAS in young children?

Evidence summary

a) Video polysomnography.

b) Polysomnography and nap polysomnography.

c) Polygraphy.

d) Nocturnal pulse oximetry.

Literature review

$\mathrm{a}+\mathrm{b}$ ) In a review of 10 studies including infants without major anomalies aged 2 weeks to 24 months, polysomnography configuration consisted of: electroencephalogram, electro-oculogram, and submental and leg electromyogram channels; oronasal thermistor; thoracic and abdominal wall movement sensors; and 
transcutaneous oxygen monitor or pulse oximetry [7]. Polysomnography has been used to diagnose OSAS in otherwise healthy infants with adenotonsillar hypertrophy and patients with craniofacial abnormalities, neuromuscular disorders or genetic syndromes $[30,44,91,94]$. Daytime nap polysomnography applied in infants and children with Down syndrome underestimates SDB severity [63]. In contrast, 4-h evening polysomnography had high sensitivity for OSAS in young patients with a variety of predisposing factors (laryngotracheomalacia, subglottic stenosis, congenital heart disease, gastro-oesophageal reflux, chronic aspiration, Down syndrome or Pierre Robin sequence) [63, 95].

c) Polygraphy (electroencephalogram, electro-oculogram or electromyogram channels not included) has been used in a small study of healthy infants and also in young children with Down syndrome or PraderWilli syndrome [96-98].

d) Pulse oximetry has been applied for diagnosing OSAS in otherwise healthy children as young as 6 months and in complex patients with Down syndrome, mucopolysaccharidosis or Pierre Robin sequence $[47,67,99,100]$.

\subsection{What are the cut-off values for the parameters of objective tools used for the diagnosis of OSAS in young children? \\ Evidence summary}

a) The 90th percentile for the frequency of obstructive apnoeas or mixed apnoeas in healthy asymptomatic young children (1-23 months old) undergoing polysomnography does not exceed 1 episode. $\mathrm{h}^{-1}$ and hypopnoeas are uncommon. Thus, the obstructive AHI is $<1$ episode $h^{-1}$ in healthy young children. The 90th percentile for the oxygen desaturation $(\geqslant 3 \%)$ of haemoglobin index is 2.2 episodes $\cdot \mathrm{h}^{-1}(1.1-1.9$ years old). Healthy infants residing at high altitude have more obstructive events and oxyhaemoglobin desaturations than infants at sea level, but these findings improve with older age.

b) The frequency of central apnoeas varies widely according to age and definition. Therefore, the definition of OSAS in children aged 1-23 months is usually based on the obstructive AHI.

c) When infants with risk factors for OSAS are considered, mild OSAS is frequently diagnosed with obstructive AHI 1-5 episodes $\cdot \mathrm{h}^{-1}$, moderate OSAS with obstructive AHI $>5-10$ episodes $\cdot \mathrm{h}^{-1}$ and severe OSAS with obstructive AHI $>10$ episodes $\cdot \mathrm{h}^{-1}$.

d) The McGill criteria for scoring nocturnal oximetry have been applied in infants with adenotonsillar hypertrophy as young as 6 months. A McGill oximetry score $>2$ has been used to define OSAS in infants with Pierre Robin sequence and moderate-to-severe OSAS in patients with Down syndrome. An oxygen desaturation $(\geqslant 4 \%)$ of haemoglobin index $>4$ episodes $\cdot \mathrm{h}^{-1}$ with median arterial oxygen saturation measured by pulse oximetry $\left(\mathrm{SpO}_{2}\right)<95 \%$ has been applied to define obstructive SDB in patients with mucopolysaccharidosis.

\section{Literature review}

a) Upper limits of obstructive and mixed apnoea index are supported by a review of 10 studies including infants without risk factors for OSAS who underwent polysomnography [7]. The minimum apnoea duration was $3 \mathrm{~s}$, which corresponds approximately to the duration of two breaths for this age group [7, 13]. These findings were confirmed for older children (1.1-1.9 years old) in a German multicentre study [8]. No hypopnoeas (reduction $\geqslant 50 \%$ in airflow signal amplitude associated with $\mathrm{SpO}_{2}$ drops $\geqslant 3 \%$ or an arousal) were noted. Higher values were reported for the 95th percentile of the obstructive apnoea index and mixed apnoea index in a study using polygraphy in a limited number of healthy infants: 3.5 and 1.1 episodes $\cdot h^{-1}$, respectively, at 1 month of age; 2.2 and 0.7 episodes $\cdot h^{-1}$, respectively, at 3 months of age [96]. For healthy infants residing in altitude $>2500 \mathrm{~m}$ above sea level, the 95th percentile value of the obstructive AHI is elevated: 27.6 episodes $\cdot \mathrm{h}^{-1}$ at age $<45$ days decreasing to 1.8 episodes $\cdot \mathrm{h}^{-1}$ at age 10-18 months [101]. The 95th percentile for the frequency of $\mathrm{SpO}_{2}$ drops $>3 \%$ during active/ rapid eye movement sleep ranges from 170.1 episodes $\cdot \mathrm{h}^{-1}$ at age $<45$ days to 68.2 episodes $\cdot \mathrm{h}^{-1}$ at age 10-18 months [101].

b) The 95th percentile for central apnoea index (cessation of airflow and respiratory effort for $\geqslant 3 \mathrm{~s}$ ) varies widely according to age: 45 episodes $\cdot \mathrm{h}^{-1}$ for 1-month-old infants and 10-20 episodes $\cdot \mathrm{h}^{-1}$ for 3- to 12 -month-old infants [7]. In the German multicentre study, the 90th percentile for central apnoea index (no airflow and respiratory effort for $\geqslant 5 \mathrm{~s}$ ) was 4.3 episodes $\cdot \mathrm{h}^{-1}$ for ages 1.1-1.9 years [8]. For infants residing in high altitude, the 95th percentile value of the central AHI is elevated: 65.4 episodes $\cdot \mathrm{h}^{-1}$ at age $<45$ days decreasing to 8.7 episodes $\cdot \mathrm{h}^{-1}$ at age $10-18$ months [101]. In view of the unique definition of central apnoea in infants and the wide variability of the upper reference limit for the central apnoea index in the first 23 months of age, in their practice, the ERS Task Force members use the obstructive AHI for diagnosing OSAS in this age group [13]. 
c) In studies reporting the efficacy of interventions for OSAS in infancy, obstructive AHI >11.5 episodes $\mathrm{h}^{-1}$ has been applied to define abnormal polysomnography [30, 91, 94]. In retrospective studies of infants $\left(<1-2\right.$ years old) with risk factors for OSAS, AHI $<1$ episodes $\cdot \mathrm{h}^{-1}$ was considered normal, and AHI values of $1-5$ episodes $\cdot \mathrm{h}^{-1}, 5-10$ or 15 episodes $\cdot \mathrm{h}^{-1}$ and $>10$ or 15 episodes $\cdot \mathrm{h}^{-1}$ were defined as mild, moderate and severe OSAS, respectively [30, 94, 102, 103]. Similar classification of OSAS severity was applied in infants with Pierre Robin sequence [91]. When infants with syndromic craniosynostosis were studied, OSAS was defined as mild with obstructive AHI $<5$ episodes $\cdot \mathrm{h}^{-1}$, moderate with obstructive AHI 5-24 episodes $\cdot \mathrm{h}^{-1}$ and severe with obstructive AHI $\geqslant 25$ episodes $\cdot \mathrm{h}^{-1}$ [44].

d) An abnormal McGill oximetry score of $\geqslant 2(\geqslant 3$ clusters of desaturation events $\geqslant 4 \%$ and $\geqslant 3$ desaturations to $\leqslant 90 \%$ ) corresponds to OSAS of at least moderate severity, but a score of 1 does not exclude OSAS [99]. In patients with Down syndrome, a McGill oximetry score $\geqslant 3$ ( $\geqslant 3$ clusters of desaturation events $\geqslant 4 \%$ and $>3$ desaturations to $<85 \%$ ) has a positive predictive value of $94 \%$ and a specificity of $98 \%$ for identifying AHI $\geqslant 2.5$ episodes $\cdot h^{-1}$ [100]. In infants with Pierre Robin sequence, a McGill oximetry score $>2$ has been applied to determine indications for nasopharyngeal airway insertion [47]. Nocturnal oximetry has been used in children with mucopolysaccharidosis to diagnose obstructive SDB [67].

\subsection{In the context of which symptoms and exam findings are objective tests used to exclude the presence of OSAS? \\ Evidence summary}

a) Parental report of snoring, apnoea, restless sleep and mouth breathing.

b) History of cyanotic spells, ALTEs or delayed growth, if there are other symptoms or signs of OSAS.

c) Nasal obstruction (adenoidal hypertrophy with or without tonsillar hypertrophy, choanal atresia and pyriform aperture stenosis).

d) Laryngomalacia as suggested by persistent stridor without or with intercostal retractions, cyanotic spells or growth failure.

e) Syndromic craniosynostosis with or without midface hypoplasia; unrepaired or repaired isolated cleft lip or palate; and marked mandibular hypoplasia.

f) Neuromuscular disorders (cerebral palsy, mitochondrial disorders and spinal muscular atrophy).

g) Complex abnormalities (achondroplasia, Beckwith-Wiedemann syndrome, Chiari malformation, Down syndrome, mucopolysaccharidoses and Prader-Willi syndrome).

\section{Literature review}

According to the clinical experience of the ERS Task Force members, a multidisciplinary team approach is usually necessary, including a sleep specialist, ear, nose and throat (ENT)/craniofacial surgeon, intensivist, respiratory physiologist, orthodontist, and others [50, 104].

$\mathrm{a}+\mathrm{b})$ A history of snoring, apnoea or, less frequently, nocturnal desaturations has been used as an indication for polysomnography in young children $[21,30]$. In patients with a history of ALTEs and symptoms or signs indicative of obstructive SDB, polysomnography has been applied to exclude OSAS [15]. OSAS may be demonstrated in up to $60 \%$ of such cases [25].

c) Adenoidal or tonsillar hypertrophy and choanal atresia are associated with OSAS [37, 105].

d) Children with laryngomalacia and intercostal retractions frequently have increased AHI $[38,39,106]$.

e) Syndromic craniosynostosis with or without midface hypoplasia is characterised by a high frequency of obstructive events in polysomnography [44]. Infants with cleft lip/and or palate have increased OSAS prevalence [46]. Polysomnography and nocturnal oximetry have been used in patients with Pierre Robin sequence to direct treatment interventions $[47,52,91]$.

f) Spinal muscular atrophy, cerebral palsy and mitochondrial disorders may be related to an elevated AHI [54-57].

g) Overall, infants with achondroplasia have increased AHI, but OSAS severity is not predicted by the size of the foramen magnum [58]. Both polysomnography and nocturnal oximetry have demonstrated increased OSAS prevalence in infants with Beckwith-Wiedemann syndrome, Chiari malformation, mucopolysaccharidosis or those with Down syndrome (especially with a history of dysphagia, gastro-oesophageal reflux disease, congenital heart disease or premature birth) $[59,60,62,67,100]$. Children with Prader-Willi syndrome aged $<2$ years have an increased frequency of obstructive events and central apnoeas $[68,69,107]$. 
Topic 4: treatment of OSAS in young children

4.1. When is OSAS in young children treated?

Evidence summary

a) OSAS in association with apparent upper airway obstruction during wakefulness (mild or severe intercostal retractions, prolonged apnoeas with cyanotic spells while awake: "obstructive awake apnoea") and without or with failure to thrive. Treatment prevents or reverses respiratory failure, pulmonary hypertension and growth delay.

b) Abnormalities in polysomnography, polygraphy or pulse oximetry in combination with snoring or "noisy" breathing, nocturnal tachypnoea, oral breathing, history of ALTEs, or delayed growth.

c) Abnormalities in polysomnography, polygraphy or pulse oximetry in association with risk factors for OSAS: nasal obstruction (e.g. adenoidal without or with tonsillar hypertrophy and choanal atresia); laryngomalacia; syndromic craniosynostosis with or without midface hypoplasia; isolated cleft lip or palate; mandibular hypoplasia (e.g. Pierre Robin sequence); or neuromuscular disorder.

\title{
Literature review
}

a) Children with OSAS and severe upper airway obstruction present even during wakefulness improve regarding symptoms and polysomnography findings following treatment interventions [38]. "Obstructive awake apnoea" was defined as complete or partial cessation of air exchange during wakefulness due to observable upper airway obstruction [75]. Severity of hypoxaemia (nocturnal oximetry) and intensity of work of breathing facilitate the choice of treatment [47]. Polysomnography is not always performed pre-operatively in children with a history of respiratory distress related to obstructive tonsils [103]. However, in such cases OSAS severity may be underestimated and thus appropriate anaesthetic and post-operative care might not be available.

b) Children with OSAS related to adenotonsillar hypertrophy or laryngomalacia and body mass index in the lower percentiles have symptom resolution and increased growth rate following adenotonsillectomy or supraglottoplasty $[20,83,94,108,109]$.

c) Improvement in symptoms and/or AHI was demonstrated in infants with OSAS and adenotonsillar hypertrophy, laryngomalacia, choanal atresia, mandibular hypoplasia or craniosynostosis syndromes with or without midface hypoplasia after surgical treatment (adenoidectomy, tonsillectomy, adenotonsillectomy, supraglottoplasty, repair of choanal atresia, mandibular distraction osteogenesis and midface advancement) $[20,30,38,39,44,52,94]$. Nasopharyngeal tube insertion in infants with Pierre Robin sequence and McGill oximetry score $>2$ resulted in improved oximetry [47].

\author{
4.2. Are there complex conditions predisposing to upper airway obstruction which make \\ treatment of OSAS a priority? \\ Evidence summary \\ a) Achondroplasia. \\ b) Beckwith-Wiedemann syndrome. \\ c) Chiari malformation. \\ d) Down syndrome. \\ e) Mucopolysaccharidoses. \\ f) Prader-Willi syndrome.
}

Literature review

a) It is controversial whether the increased mortality of infants with achondroplasia can be attributed to cervicomedullary compression and central respiratory control abnormalities resulting in central sleep apnoea [110, 111]. Although young children with achondroplasia have an increased frequency of obstructive and central apnoeas, the size of the foramen magnum is not related to the AHI, central apnoea index or desaturation index $[58,112]$.

b) Severe OSAS resolved in two infants with Beckwith-Wiedemann syndrome after division of the frenulum linguae with central tongue resection or anterior glossopexy [59].

c) Central sleep apnoea and OSAS in young patients with Chiari malformation may indicate brainstem crowding at the foramen magnum and need for decompressive surgery [60].

d) The majority of infants with Down syndrome and OSAS have severe disease and nocturnal hypoventilation, and they are predisposed to develop pulmonary hypertension $[62,113]$. 
e) Children with any type of mucopolysaccharidosis develop progressively deteriorating OSAS [67].

f) OSAS prevalence is high in patients with Prader-Willi syndrome; in 25\% of cases, OSAS is severe and improves following treatment (e.g. adenotonsillectomy) [68].

Topic 5: stepwise individualised treatment approach for OSAS in young children

5.1. What is the hierarchy of treatment interventions for OSAS in young children?

Evidence summary

a) Interventions for OSAS in young children are individualised according to aetiology, severity and morbidity.

b) Nasopharyngoscopy or drug-induced sleep endoscopy may be used to determine the type and sequence of treatment interventions.

c) In infants with OSAS due to multiple causes, surgical treatment is overall more effective in reducing symptoms than oxygen administration, use of antireflux medications or continuous positive airway pressure (CPAP) application. CPAP or non-invasive positive pressure ventilation (NPPV), tracheostomy and supraglottoplasty are equally effective in reducing the AHI.

\section{Literature review}

As was stated in 3.3, a multidisciplinary team management is frequently required, including a sleep specialist, ENT/craniofacial surgeon, intensivist, respiratory physiologist, orthodontist and other specialists $[50,104]$. Adenotonsillectomy, CPAP/NPPV and tracheostomy are interventions that are used for the treatment of OSAS attributed to various conditions predisposing to upper airway obstruction. Nasal corticosteroids and/or montelukast administered for 6-12 weeks decrease the severity of mild-to-moderate OSAS in children aged $>2$ years, but no evidence exists for younger patients [3].

a) A stepwise approach has been described in two retrospective, cohort studies of infants with Pierre Robin sequence $[91,114]$. In a prospective study of children with syndromic craniosynostosis with or without midface hypoplasia, cranial vault surgery was performed in the first year of life, followed in frequency by adenotonsillectomy, transverse widening of the hypoplastic maxilla, midface advancement, tracheostomy and ventilation [44].

b) Nasopharyngoscopy has been used in patients with Pierre Robin sequence to classify the type of pharyngeal airway obstruction and to select the type and sequence of interventions [74, 75, 115]. Drug-induced sleep endoscopy has been applied in otherwise healthy young children with OSAS to detect the level of obstruction and direct surgical interventions (e.g. adenotonsillectomy versus adenoidectomy) [116].

c) In a retrospective study of infants, surgical interventions showed better symptom resolution than oxygen administration or CPAP treatment [30]. Surgical treatment and antireflux medications were superior to no treatment regarding resolution of OSAS symptoms [30]. In another retrospective study, CPAP/NPPV, tracheostomy and supraglottoplasty were equally effective based on polysomnography [94].

\subsection{What is the efficacy of antireflux medications for OSAS related to gastro-oesophageal reflux in young children? \\ Evidence summary}

Limited data indicate that antireflux medications decrease OSAS severity in young children (e.g. those with laryngomalacia).

\section{Literature review}

Although antireflux medications are administered in up to two-thirds of infants with OSAS, there is weak evidence for improvement of treated patients versus not treated subjects [30, 94]. Although more severe laryngomalacia is associated with higher prevalence of reflux, antireflux medications do not improve apnoeas [117].

\subsection{What are the efficacy and risks of adenotonsillectomy in young children with OSAS?}

Evidence summary

a) Adenoidectomy alone is efficacious in improving OSAS symptoms and polysomnography parameters in infants ( $<12$ months), but some patients may require tonsillectomy subsequently. Adenotonsillectomy for adenotonsillar hypertrophy is efficacious in patients with craniosynostosis with or without midface hypoplasia. 
b) Young children with comorbidities (asthma, obesity, gastro-oesophageal reflux disease, Down syndrome, congenital heart disease, history of premature birth and cerebral palsy) or severe OSAS pre-operatively are at risk of residual disease post-operatively.

c) Children aged $<3$ years are at increased risk of respiratory compromise, bleeding and persistent poor oral intake after adenotonsillectomy. Risk for respiratory complications is highest in children aged $<2$ years and in those with adenoidal enlargement, nasal obstruction or cardiovascular anomalies.

\section{Literature review}

a) Adenotonsillectomy in infants with adenotonsillar hypertrophy and OSAS is accompanied by snoring resolution and improvement in growth and polysomnography findings [20, 105, 116, 118, 119]. Adenoidectomy alone is efficacious in most patients aged $\leqslant 12$ months, but OSAS recurrence may necessitate additional tonsillectomy $[120,121]$. In a prospective study of children with craniosynostosis syndromes (with or without midface hypoplasia), adenotonsillectomy was the most frequent intervention after the first year of life [44].

b) Following adenotonsillectomy, AHI $>5$ episodes $\cdot \mathrm{h}^{-1}$ was demonstrated in $20-65 \%$ with the highest prevalence of residual OSAS among patients with comorbidities [118-120].

c) Poor oral intake and dehydration are the most common complications [118, 122]. Children aged $<3$ years have double the risk for post-operative respiratory complications (e.g. laryngospasm, hypoxaemia, apnoea and increased work of breathing) compared with those aged 3-5 years, while nasal obstruction, large adenoid size and cardiovascular anomalies are significant predisposing factors $[105,118,123,124]$. Nasopharyngeal airway placement, re-intubation, supplemental oxygen, CPAP or NPPV may be required $[105,118,121,123]$. It has been recommended that children aged $<3$ years should be monitored as inpatients post-operatively due to the high risk of respiratory complications [10].

\subsection{What is the youngest age for adenotonsillectomy in children for OSAS related to adenotonsillar hypertrophy? \\ Evidence summary \\ The youngest age for adenoidectomy is 3 months and for adenotonsillectomy is 6 months.}

\section{Literature review}

These statements are supported by retrospective studies of infants diagnosed with OSAS [102, 125].

\subsection{What are the efficacy and risks of CPAP or NPPV for OSAS in young children? Evidence summary}

a) In children aged $<24$ months with moderate-to-severe OSAS who are not candidates for or do not improve after adenotonsillectomy or other surgical interventions: i) CPAP initiated at $4-6 \mathrm{cmH}_{2} \mathrm{O}$ and titrated up to $10 \mathrm{cmH}_{2} \mathrm{O}$ is an effective and well-tolerated treatment; ii) it can be applied as a temporary intervention while waiting for craniofacial surgery; iii) NPPV has been used in cases of OSAS coexisting with hypoventilation (e.g. spinal muscular atrophy type 1).

b) Most studies report minor complications. Occurrence of midface flattening has been described, but long-term consequences and potential reversibility of this finding are unknown.

c) A nasal mask is the most common interface for CPAP or NPPV; an oronasal mask is used for uncontrollable mouth leak or severe nasal obstruction.

\section{Literature review}

a) During NPPV therapy, bilevel positive airway pressure is applied, i.e. inspiratory and expiratory positive airway pressure [126, 127]. In one study of infants with OSAS, nasal CPAP (nCPAP) was initiated at $3.7 \mathrm{cmH}_{2} \mathrm{O}$ and increased by $0.3 \mathrm{cmH}_{2} \mathrm{O}$ increments until obstructive events were abolished [128]. The success rate of CPAP ranges from $38 \%$ to $100 \%$ [129]. OSAS in children aged <2 years with laryngomalacia improved with CPAP $[130,131]$. Application of CPAP or bilevel positive airway pressure is accompanied by a reduction in respiratory rate and oesophageal pressure swings indicating unloading of the respiratory muscles [132]. nCPAP $\left(6-8 \mathrm{cmH}_{2} \mathrm{O}\right)$ has been used for severe OSAS (AHI $>10$ episodes $\mathrm{h}^{-1}$ ) in infants with Pierre Robin sequence, as a bridge to craniofacial surgery, but also in cases with milder OSAS [91, 133, 134]. Retrospective studies support the use of nCPAP for moderate-to-severe OSAS in infants with cerebral palsy, achondroplasia, Beckwith-Wiedemann syndrome, Down syndrome or mucopolysaccharidosis [128, 134]. Furthermore, NPPV has been applied in infants with spinal muscular atrophy type 1 presenting with respiratory failure, paradoxical breathing and hypoventilation $[135,136]$. Nocturnal NPPV normalises the 
AHI and desaturation index, and improves inspiratory muscle synchrony $[135,136]$. Limited data support the use of high-flow nasal cannula therapy in children with nCPAP intolerance [137].

b) During periods of upper respiratory infection, nCPAP may be interrupted for a few days due to nasal obstruction and mouth leak [134]. Minor complications related to mask fit (eye or skin irritation) and nasal dryness have been noted [129]. Abdominal distension or emesis anecdotally may occur in prematurely born infants [134].

c) This statement is supported by retrospective studies $[128,134]$.

\subsection{What are the efficacy and risks of treatment interventions for OSAS related to specific conditions? \\ a) Choanal atresia or nasal pyriform aperture stenosis \\ Evidence summary}

a) Bilateral choanal atresia is a medical emergency in the neonatal period. Surgical repair has a high success rate in improving OSAS symptoms with low morbidity (bleeding, nasal septum perforation, synechiae and granulation tissue).

b) Nasal pyriform aperture stenosis is a rare cause of upper airway obstruction in neonates. Surgery is indicated for OSAS or growth failure. Surgical outcome is good, with low morbidity and prognosis depends on comorbidities.

Literature review

a) Transnasal endoscopic repair of choanal atresia has a lower rate of complications than the traditional transpalatal approach. In a meta-analysis, the success rate of the transnasal endoscopic approach was $85.3 \%$, whereas the associated complications were minor and of low frequency (14.2\%) [138]. No post-operative polysomnography data are available.

b) Surgical treatment is effective in improving nostril patency without major complications and it is applied if there is no response to humidification and nasal decongestants [76]. Post-operative polysomnography data are not available.

\section{b) Severe laryngomalacia}

Evidence summary

Supraglottoplasty improves obstructive breathing and growth rate, but its efficacy is affected by potential coexisting airway lesions. Surgical risk is low and temporary pre-operative tracheostomy may be necessary.

\section{Literature review}

Supraglottoplasty is an endoscopic procedure involving division of the aryepiglottic folds with or without removal of the redundant supra-arytenoidal mucosa. It is accompanied by improvement in AHI, oxygenation indices, ventilation and growth rate $[38-40,106]$. Persistent OSAS post-operatively occurs especially in cases with neurological or syndromic disorders or coexisting airway anomalies (subglottic stenosis and tracheomalacia) $[40-42,89,139]$. Complications are formation of granuloma, oedema, web or supraglottic stenosis [139]. Self-limited dysphagia has been reported [38].

\section{c) Syndromic craniosynostosis with or without midface hypoplasia \\ Evidence summary}

a) Adenoidectomy without or with tonsillectomy is the most frequent intervention for OSAS.

b) Nasopharyngeal airway insertion or nCPAP are used to relieve upper airway obstruction.

c) Midface advancement by distraction osteogenesis results in improved upper airway patency during sleep and it is indicated in cases of moderate-to-severe upper airway obstruction with severe exorbitism and with or without raised intracranial pressure.

\section{Literature review}

a) In a prospective study of children with OSAS due to syndromic craniosynostosis with or without midface hypoplasia, adenotonsillectomy was the most frequent treatment intervention followed by transverse widening of the hypoplastic maxilla, midface advancement, tracheostomy and mechanical ventilation [44].

b) Nasopharyngeal airway has been used to treat OSAS without or with adenoidectomy [140]. nCPAP is also an option [129]. 
c) The monobloc frontofacial advancement is technically difficult in young children and thus distraction osteogenesis techniques have been considered. Children aged $<2$ years with syndromic craniosynostosis and OSAS were subjected to midface distraction osteogenesis [141-143]. Midface advancement was accompanied by resolution of snoring, improvement in polysomnography indices and decannulation in patients with tracheostomy. Complications included cerebrospinal fluid leak and local infection at the site of the distractor pins.

\section{d) Severe mandibular hypoplasia (non-syndromic or syndromic Pierre Robin sequence) Evidence summary}

a) In cases of Pierre Robin sequence with mild upper airway obstruction (no or minimal signs of respiratory distress, McGill oximetry score $\leqslant 2$; no pharyngeal collapse on nasopharyngoscopy), prone positioning is the first step for maintaining upper airway patency.

b) In cases of moderate-to-severe OSAS (respiratory distress, McGill oximetry score $>2$ or AHI $>10$ episodes $\cdot \mathrm{h}^{-1}$ ), a nasopharyngeal airway, placement of an orthodontic appliance, tongue-to-lip adhesion (glossopexy) or nCPAP have been applied according to local experience to maintain upper airway patency and avoid mandibular distraction osteogenesis or tracheostomy. Upper airway endoscopy can facilitate treatment decisions. Tongue-to-lip adhesion may be complicated by wound rupture and aspiration pneumonia.

c) In cases of severe upper airway obstruction, endotracheal intubation and frequently tracheostomy are required to secure upper airway patency or as temporising measures until completion of mandibular distraction osteogenesis (see 5.6.e and 5.7).

d) A large proportion of infants with Pierre Robin sequence require a nasogastric or gastrostomy tube for proper feeding, whereas in milder cases special nipples or palatal obturators may be used.

\section{Literature review}

An algorithmic approach to the management of upper airway obstruction based on retrospective data and systematic review of the published literature has been presented [50, 144].

a) For $25.9 \%$ of 104 infants with Pierre Robin sequence and mild upper airway obstruction (McGill oximetry score $\leqslant 2$ ), prone positioning was adequate for maintaining upper airway patency as evidenced by polysomnography [47]. In retrospective studies without nocturnal monitoring, a much higher proportion (47.6-74.5\%) of infants responded to prone positioning [51,53, 114, 145, 146]. In one case report, tidal volume became larger and oesophageal pressure swings smaller in the prone rather than in the supine position [81]. Absence of pharyngeal collapse on upper airway endoscopy predicts efficacy of the intervention [115]. Prone positioning is usually necessary for 5-6 months, but does not allow direct observation of signs related to respiratory distress (e.g. intercostal retractions) and it might increase the risk of sudden infant death syndrome $[47,75,114]$.

b) For moderate-to-severe OSAS (McGill oximetry score $>2$ ), insertion of a nasopharyngeal tube open to room air that displaces the tongue base away from the airway is accompanied by improvement or resolution of obstruction (60.6\% of infants) [47]. Correct positioning of the tip of the nasopharyngeal airway (just beyond the base of the tongue and above the epiglottis) is confirmed by a lateral neck radiograph [47]. In a tertiary centre, patients were discharged safely home with the nasopharyngeal tube for a median duration of 8 months. Parents were taught how to suction and replace the nasopharyngeal airway if obstructed. Infrequently, a nasopharyngeal tube may be displaced upwards (recurrence of airway obstruction) or downwards (irritation of the larynx) [114]. Upper airway endoscopy not demonstrating pharyngeal collapse during inspiration facilitates the decision for removing the tube [75]. An orthodontic appliance with a velar extension that moves the tongue anteriorly may relieve upper airway obstruction in infants with isolated Pierre Robin sequence and mixed obstructive apnoea index $>3$ episodes $\cdot \mathrm{h}^{-1}$ [147]. This effect persists at 3 months of device use and is associated with an increase in growth [148]. Tongue-to-lip adhesion is another method to prevent airway obstruction by the tongue, but it is technically difficult and may be complicated by wound rupture (up to 57\% of cases) or aspiration pneumonia $[114,146]$. Its efficacy (up to $70 \%$ ) has been evaluated by polysomnography [53, 149, 150]. The procedure is most effective in cases of type I pharyngeal obstruction (see 1.4) [75]. Gastrostomy may be necessary to overcome feeding difficulties and mandibular distraction osteogenesis can be ultimately required for improving airway patency or orthodontic purposes [150]. No deficits in tongue function have been described following reversal of tongue-to-lip adhesion [53]. In one case series, nCPAP was used in $55.2 \%$ of infants with Pierre Robin sequence and AHI $>10$ episodes $\cdot h^{-1}$ (see also 5.5) [91].

c) In case series, up to $25.5 \%$ of infants with severe respiratory distress required endotracheal intubation which was followed by a nasopharyngeal airway, tracheostomy or mandibular distraction osteogenesis 
$[114,145]$. Lateral or circular pharyngeal collapse on nasopharyngoscopy predicts the need for tracheostomy and/or mandibular distraction osteogenesis [47, 114, 115, 145].

d) Nasogastric or gastrostomy tube feeding is required in many infants with Pierre Robin sequence (41.8$78.8 \%)$ to overcome feeding difficulties, but special nipples or palatal obturators have been used successfully in milder cases $[47,51,114,145]$.

\section{e) Mandibular distraction osteogenesis}

Evidence summary

a) Mandibular distraction osteogenesis has been applied in infants with OSAS related to non-syndromic or syndromic mandibular hypoplasia aged 2-3 months or younger: i) following urgent intubation or tracheostomy to allow removal of the artificial airway; ii) when upper airway obstruction, respiratory distress and hypercapnia are present without response to non-surgical treatment interventions.

b) The procedure may be complicated by local skin infection, facial scarring, nerve and tooth bud injury, disturbance of intrinsic mandibular growth, and need for tracheostomy or repeat procedure.

\section{Literature review}

$\mathrm{a}+\mathrm{b})$ External and internal metallic devices are used, which may cause facial pin migration scars and which are removed surgically after completion of the procedure [77, 151]. Resorbable internal distractors are another option [52]. In a series of infants with Pierre Robin sequence, patients with severe upper airway obstruction underwent tracheostomy as neonates, and distraction osteogenesis was initiated after the first month of life when the mandibular bone was hard enough to apply screws and pins [51]. Nevertheless, the intervention has also been reported in patients with an age range of 5 days to 12 weeks $[152,153]$. In a retrospective cohort of infants with isolated Pierre Robin sequence, mandibular distraction osteogenesis was applied to avoid tracheostomy when other measures (prone positioning, tongue-to-lip adhesion) failed to secure upper airway patency [53]. Severe respiratory distress with hypercapnia in the presence of glossoptosis combined with other airway lesions (e.g. unilateral choanal atresia, hypoplastic epiglottis, laryngomalacia or tracheal stenosis) is an additional indication for mandibular distraction osteogenesis [52]. The efficacy of the procedure in restoring upper airway patency in young children $(>80 \%)$ and the frequency of potential complications have been assessed in two meta-analyses/systematic reviews [77, 151]. Improvement in polysomnography after completion of the procedure has been demonstrated [79, 154]. Mandible traction using two parasymphyseal wires inserted under local anaesthesia has been proposed as a substitute for mandibular distraction osteogenesis [155].

\subsection{What are the efficacy and risks of tracheostomy for OSAS in young children?}

Evidence summary

a) Tracheostomy is an urgent procedure in patients with severe upper airway obstruction and a treatment option in cases with persistent symptoms when other surgical or non-surgical interventions fail to improve upper airway patency.

b) Tracheostomy can be a temporary measure until completion of craniofacial surgery.

c) Acute and life-threatening complications of tracheostomy include cannula obstruction by mucus and accidental decannulation. Long-term tracheostomy may delay acquisition of language skills.

\section{Literature review}

$\mathrm{a}+\mathrm{b})$ Tracheostomy may be required in the first month of life for upper airway obstruction due to midface or mandibular hypoplasia $[44,102,156]$. In children with craniosynostosis and midface hypoplasia, tracheostomy may be urgently required prior to craniofacial surgery [142]. In case series of infants with Pierre Robin sequence, tracheostomy was required in 5.5-20.9\% of patients and was frequently maintained beyond the first year of life $[47,51,53,114,115]$. Tracheostomy has been proposed for infants who have type II-IV pharyngeal obstruction defined by endoscopy without response to insertion of a nasopharyngeal airway (see also 1.4) [75, 115].

c) Complications of tracheostomy have been summarised in a review article (pneumothorax, pneumomediastinum, bleeding, wound infection, cannula obstruction by mucus, accidental decannulation, frequent lower respiratory tract infections, formation of granulation tissue, tracheocutaneous fistulae, laryngotracheal stenosis, tracheoinnominate artery fistula, delayed language skills acquisition and adverse effects on facial development) [157]. 


\subsection{What is the management of OSAS in young children with complex conditions?}

Evidence summary

In children with OSAS secondary to complex conditions a combination of interventions may be required.

a) Achondroplasia: OSAS may improve after adenotonsillectomy, but a nasopharyngeal airway or CPAP is necessary if upper airway obstruction persists post-operatively.

b) Chiari malformation: adenoidectomy and/or tonsillectomy, CPAP or NPPV may be required to treat OSAS, central sleep apnoea and nocturnal hypoventilation; surgical decompression of the cervicomedullary junction is accompanied by a decrease in the frequency of central apnoeas.

c) Down syndrome: adenoidectomy or adenotonsillectomy for adenoidal or tonsillar hypertrophy and supraglottoplasty for laryngomalacia have been reported. CPAP has been applied for persistent OSAS post-operatively or as first-line treatment in the absence of adenotonsillar hypertrophy. Some infants with Down syndrome outgrow OSAS within several months.

d) Mucopolysaccharidoses: adenotonsillectomy and CPAP are used to relieve upper airway obstruction, while enzyme replacement and haemopoietic stem cell transplantation target the metabolic disorder.

e) Prader-Willi syndrome: adenotonsillectomy for OSAS; oxygen therapy for central sleep apnoeas which decrease in frequency with age.

\section{Literature review}

a) Treatment interventions have been summarised in retrospective studies [158, 159].

b) Treatment of SDB in Chiari malformation has been described in retrospective studies of older children and adolescents $[60,160]$.

c) Interventions are based on low-quality evidence [161]. OSAS may resolve spontaneously in infants with Down syndrome and thus CPAP may be preferable over tracheostomy in selected cases [161].

d) In a prospective study, haemopoietic stem cell transplantation was more efficacious than enzyme replacement therapy for mucopolysaccharidosis type I in improving OSAS severity [67].

e) Resolution of central and obstructive events with age was reported in infants, most of whom were on growth hormone $[107,162]$.

Topic 6: follow-up, recognition and management of persistent OSAS

6.1. How soon after each treatment is the young child with OSAS usually re-evaluated and what outcomes are monitored?

Evidence summary

a) Recurrence of OSAS following adenotonsillectomy has been reported as early as 4-6 months post-operatively and repeat adenoidectomy may be required.

b) Following initiation of CPAP, polysomnography is repeated every 2-4 months during the first year of life and every 6 months thereafter to confirm the continued need for treatment and potentially increase the airway pressure.

c) In children with neuromuscular disorders, polygraphy or nocturnal oximetry/capnometry is performed after establishment of NPPV and repeated at least annually.

d) The efficacy of supraglottoplasty has been evaluated by polysomnography at 1-6 months post-operatively.

e) Infants with Pierre Robin sequence and moderate-to-severe OSAS may require a nasopharyngeal airway for $<12$ months. Sleep studies or nocturnal oximetry are performed as frequently as every 2 months and after removal of the artificial airway.

f) Serial polysomnographies are performed during mandibular distraction osteogenesis.

Literature review

a) In a group of children aged $<3$ years, a high rate of residual OSAS after adenotonsillectomy was found which was predicted by pre-operative disease severity [119]. Repeat adenoidectomy was performed for recurrent OSAS after adenotonsillectomy in a retrospective study [20].

b) Infants with OSAS related to anatomical abnormalities may require CPAP and potential increase of airway pressure and upgrade of nasal mask size for several years after treatment initiation, whereas OSAS may resolve in patients without apparent abnormalities [128, 129, 134]. In children of pre-school age with micrognathia, the required airway pressure can progressively reach $10 \mathrm{cmH}_{2} \mathrm{O}[128,133]$. 
TABLE 2 Similarities and differences in the diagnosis and management of obstructive sleep disordered breathing (SDB) in younger and older children (1-23 months versus 2-18 years)

Younger children

(1- 23 months)
Older children

(2-18 years)

\footnotetext{
Diagnosis

Symptoms reflecting upper airway obstruction are frequently present both during wakefulness and sleep

Adenotonsillar hypertrophy and obesity predominantly cause SDB

Various congenital, syndromic and/or genetic entities predominantly cause SDB

Feeding difficulties and growth failure may coexist with OSAS

Pulmonary hypertension may complicate OSAS, especially in patients with complex conditions

Polysomnography is the gold standard for diagnosis of OSAS

Endoscopy is especially useful to determine the level of upper airway collapse

Management

Adenotonsillectomy is the most commonly used treatment

NPPV is frequently used as first-line treatment due to a high incidence of multilevel, dynamic airway collapse

Orthodontic appliances are effective in cases of OSAS with retrognathia or malocclusion

Patients with complex conditions are prioritised for treatment

Follow-up after each treatment intervention may identify persistent OSAS

Patients on NPPV undergo nocturnal cardiorespiratory monitoring annually
}

$\begin{array}{cc}\text { Yes } & \text { No } \\ \text { No } & \text { Yes } \\ \text { Yes } & \text { No } \\ \text { Yes } & \text { No } \\ \text { Yes } & \text { Yes } \\ \text { Yes } & \text { Yes } \\ \text { Yes } & \text { No } \\ & \\ \text { No } & \text { Yes } \\ \text { Yes } & \text { No } \\ & \\ \text { No } & \text { Yes } \\ \text { Yes } & \text { Yes } \\ \text { Yes } & \text { Yes } \\ \text { Yes } & \text { Yes }\end{array}$

OSAS: obstructive sleep apnoea syndrome; NPPV: non-invasive positive pressure ventilation.

c) An expert opinion statement from the British Thoracic Society Guidelines suggests performing polygraphy or nocturnal oximetry/capnometry after establishment of NPPV and repeating it at least annually in children with neuromuscular disorders [163].

d) Improvement of OSAS after supraglottoplasty has been demonstrated in a retrospective study [38].

e) Monitoring of infants with Pierre Robin sequence and moderate-to-severe OSAS has been described in a retrospective report [47].

f) Experience with serial polysomnographies during mandibular distraction osteogenesis in infants with Pierre Robin sequence has been described in a case series [52].

Similarities and differences in the diagnosis and management of obstructive SDB in this age group compared with older children are summarised in table 2.

\section{Conclusions}

Obstructive SDB in children aged 1-23 months is a multifactorial disorder and thus objective assessment for all potential underlying abnormalities that contribute to upper airway obstruction during sleep is usually performed. To achieve complete resolution of SDB in young children, combined non-surgical and surgical interventions have been reported in the literature. Adenoidectomy with or without tonsillectomy and nCPAP are among the most frequently applied treatment measures. Tracheostomy remains an urgent procedure for severe upper airway obstruction and an option when other interventions fail to improve upper airway patency.

\section{Acknowledgements}

We thank Thomy Tonia (ERS Methodologist; Institute of Social and Preventive Medicine, University of Bern, Switzerland) for critically reviewing the manuscript.

\section{References}

1 Kaditis A, Kheirandish-Gozal L, Gozal D. Algorithm for the diagnosis and treatment of pediatric OSA: a proposal of two pediatric sleep centers. Sleep Med 2012; 13: 217-227.

2 Katz ES, D'Ambrosio CM. Pathophysiology of pediatric obstructive sleep apnea. Proc Am Thorac Soc 2008; 5 : 253-262.

3 Kaditis AG, Alonso Alvarez ML, Boudewyns A, et al. Obstructive sleep disordered breathing in 2- to 18-year-old children: diagnosis and management. Eur Respir J 2016; 47: 69-94.

4 American Thoracic Society. Standards and indications for cardiopulmonary sleep studies in children. Am J Respir Crit Care Med 1996; 153: 866-878.

5 Dayyat E, Kheirandish-Gozal L, Gozal D. Childhood obstructive sleep apnea: one or two distinct disease entities? Sleep Med Clin 2007; 2: 433-444. 

the US Preventive Services Task Force. 2017. www.ncbi.nlm.nih.gov/pubmedhealth/PMH0091057/ Date last accessed: October 6, 2017.

7 Ng DK, Chan $\mathrm{CH}$. A review of normal values of infant sleep polysomnography. Pediatr Neonatol 2013; 54: 82-87.

8 Scholle S, Wiater A, Scholle HC. Normative values of polysomnographic parameters in childhood and adolescence: cardiorespiratory parameters. Sleep Med 2011; 12: 988-996.

9 Marcus CL, Brooks LJ, Draper KA, et al. Diagnosis and management of childhood obstructive sleep apnea syndrome. Pediatrics 2012; 130: e714-e755.

10 Marcus CL, Brooks LJ, Draper KA, et al. Diagnosis and management of childhood obstructive sleep apnea syndrome. Pediatrics 2012; 130: 576-584.

11 Working Party on Sleep Physiology and Respiratory Control Disorders in Childhood. Standards for Services for Children with Disorders of Sleep Physiology. London, Royal College of Paediatrics and Child Health, 2009.

12 Iber C, Ancoli-Israel S, Chesson A, et al. The AASM Manual for the Scoring of Sleep and Associated Events: Rules, Terminology and Technical Specifications. 1st Edn. Westchester, American Academy of Sleep Medicine, 2007.

13 Berry RB, Budhiraja R, Gottlieb DJ, et al. Rules for scoring respiratory events in sleep: update of the 2007 AASM Manual for the Scoring of Sleep and Associated Events. Deliberations of the Sleep Apnea Definitions Task Force of the American Academy of Sleep Medicine. J Clin Sleep Med 2012; 8: 597-619.

14 Wise MS, Nichols CD, Grigg-Damberger MM, et al. Executive summary of respiratory indications for polysomnography in children: an evidence-based review. Sleep 2011; 34: 389-398.

15 Aurora RN, Zak RS, Karippot A, et al. Practice parameters for the respiratory indications for polysomnography in children. Sleep 2011; 34: 379-388.

16 American Academy of Neurology. Clinical Practice Guideline Process Manual. St Paul, American Academy of Neurology, 2011.

17 Piteo AM, Lushington K, Roberts RM, et al. Prevalence of snoring and associated factors in infancy. Sleep Med $2011 ; 12: 787-792$.

18 Montgomery-Downs HE, Gozal D. Sleep habits and risk factors for sleep-disordered breathing in infants and young toddlers in Louisville, Kentucky. Sleep Med 2006; 7: 211-219.

19 Kalra M, Lemasters G, Bernstein D, et al. Atopy as a risk factor for habitual snoring at age 1 year. Chest 2006; 129: 942-946.

20 Greenfeld M, Tauman R, DeRowe A, et al. Obstructive sleep apnea syndrome due to adenotonsillar hypertrophy in infants. Int J Pediatr Otorhinolaryngol 2003; 67: 1055-1060.

21 Leiberman A, Tal A, Brama I, et al. Obstructive sleep apnea in young infants. Int J Pediatr Otorhinolaryngol 1988; 16: 39-44.

22 Bonuck KA, Chervin RD, Cole TJ, et al. Prevalence and persistence of sleep disordered breathing symptoms in young children: a 6-year population-based cohort study. Sleep 2011; 34: 875-884.

23 Guilleminault C, Ariagno R, Korobkin R, et al. Mixed and obstructive sleep apnea and near miss for sudden infant death syndrome: 2. Comparison of near miss and normal control infants by age. Pediatrics 1979; 64: 882-891.

24 Harrington C, Kirjavainen T, Teng A, et al. Altered autonomic function and reduced arousability in apparent life-threatening event infants with obstructive sleep apnea. Am J Respir Crit Care Med 2002; 165: 1048-1054.

25 Guilleminault C, Pelayo R, Leger D, et al. Apparent life-threatening events, facial dysmorphia and sleep-disordered breathing. Eur J Pediatr 2000; 159: 444-449.

26 Guilleminault C, Souquet M, Ariagno RL, et al. Five cases of near-miss sudden infant death syndrome and development of obstructive sleep apnea syndrome. Pediatrics 1984; 73: 71-78.

27 Guilleminault C, Stoohs R. From apnea of infancy to obstructive sleep apnea syndrome in the young child. Chest 1992; 102: 1065-1071.

28 Rabasco J, Vigo A, Vitelli O, et al. Apparent life-threatening events could be a wake-up call for sleep disordered breathing. Pediatr Pulmonol 2016; 51: 1403-1408.

29 Sanchez I, Vega-Briceno L, Munoz C, et al. Polysomnographic findings in 320 infants evaluated for apneic events. Pediatr Pulmonol 2006; 41: 215-221.

30 Ramgopal S, Kothare SV, Rana M, et al. Obstructive sleep apnea in infancy: a 7-year experience at a pediatric sleep center. Pediatr Pulmonol 2014; 49: 554-560.

31 Wasilewska J, Kaczmarski M. Sleep-related breathing disorders in small children with nocturnal acid gastro-oesophageal reflux. Rocz Akad Med Bialymst 2004; 49: 98-102.

32 Arad-Cohen N, Cohen A, Tirosh E. The relationship between gastroesophageal reflux and apnea in infants. J Pediatr 2000; 137: 321-326.

33 Qubty WF, Mrelashvili A, Kotagal S, et al. Comorbidities in infants with obstructive sleep apnea. J Clin Sleep Med 2014; 10: 1213-1216.

34 Bonuck KA, Freeman K, Henderson J. Growth and growth biomarker changes after adenotonsillectomy: systematic review and meta-analysis. Arch Dis Child 2009; 94: 83-91.

35 Katz ES, Mitchell RB, D’Ambrosio CM. Obstructive sleep apnea in infants. Am J Respir Crit Care Med 2012; 185: $805-816$.

36 Abreu e Silva FA, MacFadyen UM, Williams A, et al. Sleep apnoea during upper respiratory infection and metabolic alkalosis in infancy. Arch Dis Child 1986; 61: 1056-1062.

37 Samadi DS, Shah UK, Handler SD. Choanal atresia: a twenty-year review of medical comorbidities and surgical outcomes. Laryngoscope 2003; 113: 254-258.

38 Powitzky R, Stoner J, Fisher T, et al. Changes in sleep apnea after supraglottoplasty in infants with laryngomalacia. Int J Pediatr Otorhinolaryngol 2011; 75: 1234-1239.

39 Zafereo ME, Taylor RJ, Pereira KD. Supraglottoplasty for laryngomalacia with obstructive sleep apnea. Laryngoscope 2008; 118: 1873-1877.

40 Marcus CL, Crockett DM, Ward SL. Evaluation of epiglottoplasty as treatment for severe laryngomalacia J Pediatr 1990; 117: 706-710. 


43

Driessen C, Jo0sten KF, Bannir

craniosynostosis? A prospective cohort study. Arch Dis Child 2013; 98: 538-543.

Tan HL, Kheirandish-Gozal L, Abel F, et al. Craniofacial syndromes and sleep-related breathing disorders. Sleep Med Rev 2016; 27: 74-88.

46 MacLean JE, Fitzsimons D, Fitzgerald DA, et al. The spectrum of sleep-disordered breathing symptoms and respiratory events in infants with cleft lip and/or palate. Arch Dis Child 2012; 97: 1058-1063.

47 Abel F, Bajaj Y, Wyatt M, et al. The successful use of the nasopharyngeal airway in Pierre Robin sequence: an 11-year experience. Arch Dis Child 2012; 97: 331-334.

48 Breugem CC, Evans KN, Poets CF, et al. Best practices for the diagnosis and evaluation of infants with Robin sequence: a clinical consensus report. JAMA Pediatr 2016; 170: 894-902.

49 Rathe M, Rayyan M, Schoenaers J, et al. Pierre Robin sequence: management of respiratory and feeding complications during the first year of life in a tertiary referral centre. Int J Pediatr Otorhinolaryngol 2015; 79: 1206-1212.

50 Evans KN, Sie KC, Hopper RA, et al. Robin sequence: from diagnosis to development of an effective management plan. Pediatrics 2011; 127: 936-948.

51 van Lieshout MJ, Joosten KF, Hoeve HL, et al. Unravelling Robin sequence: considerations of diagnosis and treatment. Laryngoscope 2014; 124: E203-E209.

52 Cheng AT, Corke M, Loughran-Fowlds A, et al. Distraction osteogenesis and glossopexy for Robin sequence with airway obstruction. ANZ J Surg 2011; 81: 320-325.

53 Schaefer RB, Stadler JA III, Gosain AK. To distract or not to distract: an algorithm for airway management in isolated Pierre Robin sequence. Plast Reconstr Surg 2004; 113: 1113-1125.

54 Mosquera RA, Koenig MK, Adejumo RB, et al. Sleep disordered breathing in children with mitochondrial disease. Pulm Med 2014; 2014: 467576.

55 Kotagal S, Gibbons VP, Stith JA. Sleep abnormalities in patients with severe cerebral palsy. Dev Med Child Neurol 1994; 36: 304-311.

56 Testa MB, Pavone M, Bertini E, et al. Sleep-disordered breathing in spinal muscular atrophy types 1 and 2 . Am $J$ Phys Med Rehabil 2005; 84: 666-670.

57 Verrillo E, Bruni O, Pavone M, et al. Sleep architecture in infants with spinal muscular atrophy type 1. Sleep Med 2014; 15: 1246-1250.

58 Ednick M, Tinkle BT, Phromchairak J, et al. Sleep-related respiratory abnormalities and arousal pattern in achondroplasia during early infancy. J Pediatr 2009; 155: 510-515.

59 Kamata S, Kamiyama M, Sawai T, et al. Assessment of obstructive apnea by using polysomnography and surgical treatment in patients with Beckwith-Wiedemann syndrome. J Pediatr Surg 2005; 40: E17-E19.

60 Khatwa U, Ramgopal S, Mylavarapu A, et al. MRI findings and sleep apnea in children with Chiari I malformation. Pediatr Neurol 2013; 48: 299-307.

61 Alsaadi MM, Iqbal SM, Elgamal EA, et al. Sleep-disordered breathing in children with Chiari malformation type II and myelomeningocele. Pediatr Int 2012; 54: 623-626.

62 Goffinski A, Stanley MA, Shepherd N, et al. Obstructive sleep apnea in young infants with Down syndrome evaluated in a Down syndrome specialty clinic. Am J Med Genet 2015; 167A: 324-330.

63 Marcus CL, Keens TG, Bautista DB, et al. Obstructive sleep apnea in children with Down syndrome. Pediatrics 1991; 88: 132-139.

64 Shott SR, Amin R, Chini B, et al. Obstructive sleep apnea: should all children with Down syndrome be tested? Arch Otolaryngol Head Neck Surg 2006; 132: 432-436.

65 Lin SC, Davey MJ, Horne RS, et al. Screening for obstructive sleep apnea in children with Down syndrome. J Pediatr 2014; 165: 117-122.

66 Nashed A, Al-Saleh S, Gibbons J, et al. Sleep-related breathing in children with mucopolysaccharidosis. J Inherit Metab Dis 2009; 32: 544-550.

67 Pal AR, Langereis EJ, Saif MA, et al. Sleep disordered breathing in mucopolysaccharidosis I: a multivariate analysis of patient, therapeutic and metabolic correlators modifying long term clinical outcome. Orphanet $J$ Rare Dis 2015; 10: 42.

68 Sedky K, Bennett DS, Pumariega A. Prader Willi syndrome and obstructive sleep apnea: co-occurrence in the pediatric population. J Clin Sleep Med 2014; 10: 403-409.

69 Cohen M, Hamilton J, Narang I. Clinically important age-related differences in sleep related disordered breathing in infants and children with Prader-Willi Syndrome. PLoS One 2014; 9: e101012.

70 Croft CB, Thomson HG, Samuels MP, et al. Endoscopic evaluation and treatment of sleep-associated upper airway obstruction in infants and young children. Clin Otolaryngol Allied Sci 1990; 15: 209-216.

71 Goldberg S, Shatz A, Picard E, et al. Endoscopic findings in children with obstructive sleep apnea: effects of age and hypotonia. Pediatr Pulmonol 2005; 40: 205-210.

72 Mitchell RB, Call E, Kelly J. Diagnosis and therapy for airway obstruction in children with Down syndrome. Arch Otolaryngol Head Neck Surg 2003; 129: 642-645.

73 Bravo G, Ysunza A, Arrieta J, et al. Videonasopharyngoscopy is useful for identifying children with Pierre Robin sequence and severe obstructive sleep apnea. Int J Pediatr Otorhinolaryngol 2005; 69: 27-33.

74 Sher AE, Shprintzen RJ, Thorpy MJ. Endoscopic observations of obstructive sleep apnea in children with anomalous upper airways: predictive and therapeutic value. Int J Pediatr Otorhinolaryngol 1986; 11: $135-146$.

75 Sher AE. Mechanisms of airway obstruction in Robin sequence: implications for treatment. Cleft Palate Craniofac J 1992; 29: 224-231.

76 Visvanathan V, Wynne DM. Congenital nasal pyriform aperture stenosis: a report of 10 cases and literature review. Int J Pediatr Otorhinolaryngol 2012; 76: 28-30. 
Paes EC, Mink van der Molen AB, Muradin MS, et al. A systematic review on the outcome of mandibular distraction osteogenesis in infants suffering Robin sequence. Clin Oral Investig 2013; 17: 1807-1820.

Rachmiel A, Srouji S, Emodi O, et al. Distraction osteogenesis for tracheostomy dependent children with severe micrognathia. J Craniofac Surg 2012; 23: 459-463.

79 Looby JF, Schendel SA, Lorenz HP, et al. Airway analysis: with bilateral distraction of the infant mandible. J Craniofac Surg 2009; 20: 1341-1346.

Tal A, Leiberman A, Margulis G, et al. Ventricular dysfunction in children with obstructive sleep apnea: radionuclide assessment. Pediatr Pulmonol 1988; 4: 139-143.

81 Cogswell JJ, Easton DM. Cor pulmonale in the Pierre Robin syndrome. Arch Dis Child 1974; 49: 905-908.

82 Levine OR, Simpser M. Alveolar hypoventilation and cor pulmonale associated with chronic airway obstruction in infants with Down syndrome. Clin Pediatr 1982; 21: 25-29.

83 Czechowicz JA, Chang KW. Catch-up growth in infants with laryngomalacia after supraglottoplasty. Int J Pediatr Otorhinolaryngol 2015; 79: 1333-1336.

84 Bonuck K, Freeman K, Chervin RD, et al. Sleep-disordered breathing in a population-based cohort: behavioral outcomes at 4 and 7 years. Pediatrics 2012; 129: e857-e865.

85 Piteo AM, Kennedy JD, Roberts RM, et al. Snoring and cognitive development in infancy. Sleep Med 2011; 12: 981-987.

86 Piteo AM, Lushington K, Roberts RM, et al. Parental-reported snoring from the first month of life and cognitive development at 12 months of age. Sleep Med 2011; 12: 975-980.

87 Montgomery-Downs HE, Gozal D. Snore-associated sleep fragmentation in infancy: mental development effects and contribution of secondhand cigarette smoke exposure. Pediatrics 2006; 117: e496-e502.

88 Smith CB, Walker K, Badawi N, et al. Impact of sleep and breathing in infancy on outcomes at three years of age for children with cleft lip and/or palate. Sleep 2014; 37: 919-925.

89 Durvasula VS, Lawson BR, Bower CM, et al. Supraglottoplasty outcomes in neurologically affected and syndromic children. JAMA Otolaryngol Head Neck Surg 2014; 140: 704-711.

90 Garritano FG, Carr MM. Characteristics of patients undergoing supraglottoplasty for laryngomalacia. Int $J$ Pediatr Otorhinolaryngol 2014; 78: 1095-1100.

91 Daniel M, Bailey S, Walker K, et al. Airway, feeding and growth in infants with Robin sequence and sleep apnoea. Int J Pediatr Otorhinolaryngol 2013; 77: 499-503.

92 Robison JG, Wilson C, Otteson TD, et al. Increased Eustachian tube dysfunction in infants with obstructive sleep apnea. Laryngoscope 2012; 122: 1170-1177.

93 Mitchell RB, Call E, Kelly J. Ear, nose and throat disorders in children with Down syndrome. Laryngoscope 2003; 113: 259-263.

94 Leonardis RL, Robison JG, Otteson TD. Evaluating the management of obstructive sleep apnea in neonates and infants. JAMA Otolaryngol Head Neck Surg 2013; 139: 139-146.

95 Kahlke PE, Witmans MB, Alabdoulsalam T, et al. Full-night versus $4 \mathrm{~h}$ evening polysomnography in children less than 2 years of age. Sleep Med 2013; 14: 177-182.

96 Brockmann PE, Poets A, Poets CF. Reference values for respiratory events in overnight polygraphy from infants aged 1 and 3 months. Sleep Med 2013; 14: 1323-1327.

97 Stebbens VA, Dennis J, Samuels MP, et al. Sleep related upper airway obstruction in a cohort with Down's syndrome. Arch Dis Child 1991; 66: 1333-1338.

98 Pavone M, Caldarelli V, Khirani S, et al. Sleep disordered breathing in patients with Prader-Willi syndrome: a multicenter study. Pediatr Pulmonol 2015; 50: 1354-1359.

99 Brouillette RT, Morielli A, Leimanis A, et al. Nocturnal pulse oximetry as an abbreviated testing modality for pediatric obstructive sleep apnea. Pediatrics 2000; 105: 405-412.

100 Coverstone AM, Bird M, Sicard M, et al. Overnight pulse oximetry for evaluation of sleep apnea among children with trisomy 21. J Clin Sleep Med 2014; 10: 1309-1315.

101 Duenas-Meza E, Bazurto-Zapata MA, Gozal D, et al. Overnight polysomnographic characteristics and oxygen saturation of healthy infants, 1 to 18 months of age, born and residing at high altitude $(2,640$ meters $)$. Chest 2015; 148: 120-127.

102 Robison JG, Wilson C, Otteson TD, et al. Analysis of outcomes in treatment of obstructive sleep apnea in infants. Laryngoscope 2013; 123: 2306-2314.

103 Cote V, Ruiz AG, Perkins J, et al. Characteristics of children under 2 years of age undergoing tonsillectomy for upper airway obstruction. Int J Pediatr Otorhinolaryngol 2015; 79: 903-908.

104 Bull MJ, Committee on Genetics. Health supervision for children with Down syndrome. Pediatrics 2011; 128: 393-406.

105 Brigance JS, Miyamoto RC, Schilt P, et al. Surgical management of obstructive sleep apnea in infants and young toddlers. Otolaryngol Head Neck Surg 2009; 140: 912-916.

106 O'Connor TE, Bumbak P, Vijayasekaran S. Objective assessment of supraglottoplasty outcomes using polysomnography. Int J Pediatr Otorhinolaryngol 2009; 73: 1211-1216.

107 Urquhart DS, Gulliver T, Williams G, et al. Central sleep-disordered breathing and the effects of oxygen therapy in infants with Prader-Willi syndrome. Arch Dis Child 2013; 98: 592-595.

108 Nachalon Y, Lowenthal N, Greenberg-Dotan S, et al. Inflammation and growth in young children with obstructive sleep apnea syndrome before and after adenotonsillectomy. Mediators Inflamm 2014; 2014: 146893.

109 Shatz A. Indications and outcomes of adenoidectomy in infancy. Ann Otol Rhinol Laryngol 2004; 113: 835-838.

110 Simmons K, Hashmi SS, Scheuerle A, et al. Mortality in babies with achondroplasia: revisited. Birth Defects Res A Clin Mol Teratol 2014; 100: 247-249.

111 White KK, Bompadre V, Goldberg MJ, et al. Best practices in the evaluation and treatment of foramen magnum stenosis in achondroplasia during infancy. Am J Med Genet 2016; 170A: 42-51.

112 White KK, Parnell SE, Kifle Y, et al. Is there a correlation between sleep disordered breathing and foramen magnum stenosis in children with achondroplasia? Am J Med Genet 2016; 170A: 32-41.

113 Jacobs IN, Gray RF, Todd NW. Upper airway obstruction in children with Down syndrome. Arch Otolaryngol Head Neck Surg 1996; 122: 945-950. 
114 Li HY, Lo LJ, Chen KS, et al. Robin sequence: review of treatment modalities for airway obstruction in 110 cases. Int J Pediatr Otorhinolaryngol 2002; 65: 45-51.

115 Marques IL, de Sousa TV, Carneiro AF, et al. Clinical experience with infants with Robin sequence: a prospective study. Cleft Palate Craniofac J 2001; 38: 171-178.

116 Boudewyns A, Van de Heyning P, Verhulst S. Drug-induced sedation endoscopy in children <2 years with obstructive sleep apnea syndrome: upper airway findings and treatment outcomes. Eur Arch Otorhinolaryngol 2017; 274: 2319-2325.

117 Hartl TT, Chadha NK. A systematic review of laryngomalacia and acid reflux. Otolaryngol Head Neck Surg 2012; 147: 619-626.

118 Mitchell RB, Kelly J. Outcome of adenotonsillectomy for obstructive sleep apnea in children under 3 years. Otolaryngol Head Neck Surg 2005; 132: 681-684.

119 Nath A, Emani J, Suskind DL, et al. Predictors of persistent sleep apnea after surgery in children younger than 3 years. JAMA Otolaryngol Head Neck Surg 2013; 139: 1002-1008.

120 Cheng J, Elden L. Outcomes in children under 12 months of age undergoing adenotonsillectomy for sleep-disordered breathing. Laryngoscope 2013; 123: 2281-2284.

121 Werle AH, Nicklaus PJ, Kirse DJ, et al. A retrospective study of tonsillectomy in the under 2-year-old child: indications, perioperative management, and complications. Int J Pediatr Otorhinolaryngol 2003; 67: 453-460.

122 Spencer DJ, Jones JE. Complications of adenotonsillectomy in patients younger than 3 years. Arch Otolaryngol Head Neck Surg 2012; 138: 335-339.

123 Statham MM, Elluru RG, Buncher R, et al. Adenotonsillectomy for obstructive sleep apnea syndrome in young children: prevalence of pulmonary complications. Arch Otolaryngol Head Neck Surg 2006; 132: 476-480.

124 McCormick ME, Sheyn A, Haupert M, et al. Predicting complications after adenotonsillectomy in children 3 years old and younger. Int J Pediatr Otorhinolaryngol 2011; 75: 1391-1394.

125 Slovik Y, Tal A, Shapira Y, et al. Complications of adenotonsillectomy in children with OSAS younger than 2 years of age. Int J Pediatr Otorhinolaryngol 2003; 67: 847-851.

126 Kushida CA, Chediak A, Berry RB, et al. Clinical guidelines for the manual titration of positive airway pressure in patients with obstructive sleep apnea. J Clin Sleep Med 2008; 4: 157-171.

127 Berry RB, Chediak A, Brown LK, et al. Best clinical practices for the sleep center adjustment of noninvasive positive pressure ventilation (NPPV) in stable chronic alveolar hypoventilation syndromes. J Clin Sleep Med 2010; 6: 491-509.

128 McNamara F, Sullivan CE. Obstructive sleep apnea in infants and its management with nasal continuous positive airway pressure. Chest 1999; 116: 10-16.

129 Massa F, Gonsalez S, Laverty A, et al. The use of nasal continuous positive airway pressure to treat obstructive sleep apnoea. Arch Dis Child 2002; 87: 438-443.

130 Downey R III, Perkin RM, MacQuarrie J. Nasal continuous positive airway pressure use in children with obstructive sleep apnea younger than 2 years of age. Chest 2000; 117: 1608-1612.

131 Wormald R, Naude A, Rowley H. Non-invasive ventilation in children with upper airway obstruction. Int J Pediatr Otorhinolaryngol 2009; 73: 551-554.

132 Essouri S, Nicot F, Clement A, et al. Noninvasive positive pressure ventilation in infants with upper airway obstruction: comparison of continuous and bilevel positive pressure. Intensive Care Med 2005; 31: 574-580.

133 Amaddeo A, Abadie V, Chalouhi C, et al. Continuous positive airway pressure for upper airway obstruction in infants with Pierre Robin sequence. Plast Reconstr Surg 2016; 137: 609-612.

134 Guilleminault C, Pelayo R, Clerk A, et al. Home nasal continuous positive airway pressure in infants with sleep-disordered breathing. J Pediatr 1995; 127: 905-912.

135 Chatwin M, Bush A, Simonds AK. Outcome of goal-directed non-invasive ventilation and mechanical insufflation/exsufflation in spinal muscular atrophy type I. Arch Dis Child 2011; 96: 426-432.

136 Petrone $\mathrm{A}$, Pavone $\mathrm{M}$, Testa MB, et al. Noninvasive ventilation in children with spinal muscular atrophy types 1 and 2. Am J Phys Med Rehab 2007; 86: 216-221.

137 Joseph L, Goldberg S, Shitrit M, et al. High-flow nasal cannula therapy for obstructive sleep apnea in children. J Clin Sleep Med 2015; 11: 1007-1010.

138 Durmaz A, Tosun F, Yldrm N, et al. Transnasal endoscopic repair of choanal atresia: results of 13 cases and meta-analysis. J Craniofac Surg 2008; 19: 1270-1274.

139 Denoyelle F, Mondain M, Gresillon N, et al. Failures and complications of supraglottoplasty in children. Arch Otolaryngol Head Neck Surg 2003; 129: 1077-1080.

140 Ahmed J, Marucci D, Cochrane L, et al. The role of the nasopharyngeal airway for obstructive sleep apnea in syndromic craniosynostosis. J Craniofac Surg 2008; 19: 659-663.

141 Coeugniet E, Dhellemmes $\mathrm{P}$, Vinchon M, et al. Midfacial distraction without osteotomy using a transfacial pin and external devices. J Craniofac Surg 2012; 23: 184-189.

142 Ahmad F, Cobb AR, Mills C, et al. Frontofacial monobloc distraction in the very young: a review of 12 consecutive cases. Plast Reconstr Surg 2012; 129: 488e-497e.

143 Mitsukawa N, Kaneko T, Saiga A, et al. Early midfacial distraction for syndromic craniosynostotic patients with obstructive sleep apnoea. J Plast Reconstr Aesthet Surg 2013; 66: 1206-1211.

144 Paes EC, van Nunen DP, Speleman L, et al. A pragmatic approach to infants with Robin sequence: a retrospective cohort study and presence of a treatment algorithm. Clin Oral Investig 2015; 19: 2101-2114.

145 Meyer AC, Lidsky ME, Sampson DE, et al. Airway interventions in children with Pierre Robin Sequence. Otolaryngol Head Neck Surg 2008; 138: 782-787.

146 Kirschner RE, Low DW, Randall P, et al. Surgical airway management in Pierre Robin sequence: is there a role for tongue-lip adhesion? Cleft Palate Craniofac J 2003; 40: 13-18.

147 Buchenau W, Urschitz MS, Sautermeister J, et al. A randomized clinical trial of a new orthodontic appliance to improve upper airway obstruction in infants with Pierre Robin sequence. J Pediatr 2007; 151: 145-149.

148 Buchenau W, Wenzel S, Bacher M, et al. Functional treatment of airway obstruction and feeding problems in infants with Robin sequence. Arch Dis Child Fetal Neonatal Ed 2017; 102: F142-F146.

149 Gilhooly JT, Smith JD, Howell LL, et al. Bedside polysomnography as an adjunct in the management of infants with Robin sequence. Plast Reconstr Surg 1993; 92: 23-27. 
Denny AD, Amm CA, Schaefer RB. Outcomes of tongue-lip adhesion for neonatal respiratory distress caused by Pierre Robin sequence. J Craniofac Surg 2004; 15: 819-823.

151 Ow AT, Cheung LK. Meta-analysis of mandibular distraction osteogenesis: clinical applications and functional outcomes. Plast Reconstr Surg 2008; 121: 54e-69e.

152 Scott AR, Tibesar RJ, Lander TA, et al. Mandibular distraction osteogenesis in infants younger than 3 months. Arch Facial Plast Surg 2011; 13: 173-179.

153 Miloro M. Mandibular distraction osteogenesis for pediatric airway management. J Oral Maxillofac Surg 2010; 68: $1512-1523$.

154 Morovic CG, Monasterio L. Distraction osteogenesis for obstructive apneas in patients with congenital craniofacial malformations. Plast Reconstr Surg 2000; 105: 2324-2330.

155 Baciliero U, Spanio di Spilimbergo S, Riga M, et al. Respiratory distress in Pierre Robin sequence: an experience with mandible traction by wires. Int J Oral Maxillofac Surg 2011; 40: 464-470.

156 Perkins JA, Sie KC, Milczuk H, et al. Airway management in children with craniofacial anomalies. Cleft Palate Craniofac J 1997; 34: 135-140.

157 Kremer B, Botos-Kremer AI, Eckel HE, et al. Indications, complications, and surgical techniques for pediatric tracheostomies - an update. J Pediatr Surg 2002; 37: 1556-1562.

158 Tasker RC, Dundas I, Laverty A, et al. Distinct patterns of respiratory difficulty in young children with achondroplasia: a clinical, sleep, and lung function study. Arch Dis Child 1998; 79: 99-108.

159 Afsharpaiman S, Sillence DO, Sheikhvatan M, et al. Respiratory events and obstructive sleep apnea in children with achondroplasia: investigation and treatment outcomes. Sleep Breath 2011; 15: 755-761.

160 Amin R, Sayal P, Sayal A, et al. The association between sleep-disordered breathing and magnetic resonance imaging findings in a pediatric cohort with Chiari 1 malformation. Can Respir J 2015; 22: 31-36.

161 Rosen D. Some infants with Down syndrome spontaneously outgrow their obstructive sleep apnea. Clin Pediatr 2010; 49: 1068-1071.

162 Khayat A, Narang I, Bin-Hasan S, et al. Longitudinal evaluation of sleep disordered breathing in infants with Prader-Willi syndrome. Arch Dis Child 2017; 102: 638-642.

163 Hull J, Aniapravan R, Chan E, et al. British Thoracic Society guideline for respiratory management of children with neuromuscular weakness. Thorax 2012; 67: Suppl. 1, i1-i40. 